Int. J. Dev. Biol. 62: 491-505 (2018)

https://doi.org/10.1387/ijdb.180123sj

\title{
Wound healing, cellular regeneration and plasticity: the elegans way
}

\author{
LAURA VIBERT, ANNE DAULNY and SOPHIE JARRIAULT* \\ Department of Development and Stem Cells, IGBMC (Institut de Génétique et de Biologie Moléculaire et Cellulaire), \\ CNRS UMR 7104/INSERM U1258, Université de Strasbourg, Strasbourg, France
}

\begin{abstract}
Regeneration and wound healing are complex processes that allow organs and tissues to regain their integrity and functionality after injury. Wound healing, a key property of epithelia, involves tissue closure that in some cases leads to scar formation. Regeneration, a process rather limited in mammals, is the capacity to regrow (parts of) an organ or a tissue, after damage or amputation. What are the properties of organs and the features of tissue permitting functional regrowth and repair? What are the cellular and molecular mechanisms underlying these processes? These questions are crucial both in fundamental and applied contexts, with important medical implications. The mechanisms and cells underlying tissue repair have thus been the focus of intense investigation. The last decades have seen rapid progress in the domain and new models emerging. Here, we review the fundamental advances and the perspectives that the use of $C$. elegans as a model have brought to the mechanisms of wound healing and cellular plasticity, axon regeneration and transdifferentiation in vivo.
\end{abstract}

KEY WORDS: regeneration, wound healing, cellular plasticity, transdifferentiation, innate immune system (axotomy)

\section{Introduction}

Regenerative and wound healing capacities allow organisms to repair and regrow body parts after injuries. In humans, epithelia, including skin, intestine and lung, can heal and regrow, and a few organs, such as the kidney, endometrium and liver exhibit some regenerative abilities (Barker, 2014; Chou et al., 2014; Gargett et al., 2012; Kotton and Morrisey, 2014; Mann et al., 2011; Michalopoulos, 2007). Regenerative capacities exist within all the metazoan phyla (Bely and Nyberg 2010; Sanchez Alvarado and Tsonis, 2006) and intensive research has focused on the underlying mechanisms.

\section{Diverse regenerative mechanisms have been revealed through cellular tracking}

The origin of the regenerating cells and the cellular path(s) they undertake to replenish the missing tissues have been the subject of many studies, leading to conflicting reports on the cellular replacement strategies. Strategies involving proliferation of endogenous replacement cells, be it resident stem cells or duplications of mature cells, have been opposed to strategies involving cellular plasticity, either through the proliferation of a dedifferentiated intermediate or via cell type conversion (aka transdifferentiation or direct reprogramming). Initially, the absence of single cell markers and of accurate lineage-tracing methods led to controversies or uncertainties concerning the origin of cells involved in regeneration in organs. Recent technical advances have improved our ability to track cell fates. For example, cellular labelling techniques using fluorophores, such as GFP or mCherry, allowed endogenous induced cells or transgenic grafted cells to be followed to determine their cellular potential, meaning the number of specific cell fates they could produce (Tanaka and Reddien, 2011). The study of muscle regeneration revealed the diversity of mechanisms that can be observed for one tissue. Striated muscle of the Xenopus tadpole tail regenerate thanks to muscle stem cells, called satellite cells (Chen et al., 2006). While this seems also true during Axolotl limb regeneration, in another salamander, the newt, myofiber fragmentation resulting in proliferating mononucleated cells was also shown to contribute to skeletal muscle regeneration (Sandoval-Guzman et al., 2014). In addition, cells were found to exhibit varied degrees of cellular potential during regeneration. For instance, muscle cells have restricted developmental potential in the axolotl and can only give rise to other muscle cells, whereas in the newt they can potentially give rise to cartilage as well (Kragl et al., 2009;

Abbreviations used in this paper: AMP, anti-microbial peptide; GFP, green fluorescent protein; ROS, reactive oxygen species; $\mathrm{Td}$, transdifferentiation.

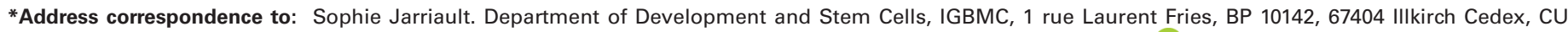

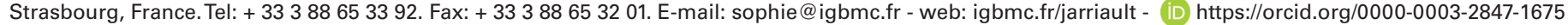


TABLE 1

\section{ADVANTAGES OF $C$. ELEGANS AS A MODEL FOR WOUND HEALING AND REGENERATIVE STUDIES}

\begin{tabular}{|c|c|c|}
\hline & C. elegans & References \\
\hline $\begin{array}{l}\text { Simple culture conditions, little space } \\
\text { requirement }\end{array}$ & Petri-dishes containing agar and layer of the bacterium Escherichia coli & Stiernagle, 2006 \\
\hline Compact annotated genome & $\begin{array}{l}\text { Sequenced: a list of } C \text {. elegans genes with human orthologues has been published ( } \approx 38 \% \text { of } C \text {. elegans } \\
\text { genes) }\end{array}$ & Shaye and Greenwald, 2011 \\
\hline Short life cycle & $\begin{array}{l}3 \text { days at } 25^{\circ} \mathrm{C} \\
\text { Four larval stages interrupted by molts }\end{array}$ & Stiernagle, 2006 \\
\hline General Anatomical advantages & $\begin{array}{l}1 \mathrm{~mm} \text { long at adult stage } \\
\text { Transparency } \\
\text { somatic lineage known }\end{array}$ & $\begin{array}{l}\text { Sulston and Horvitz, 1977; } \\
\text { Sulston et al., 1983; } \\
\text { Corsi et al., } 2015\end{array}$ \\
\hline Statistics & Powerful statistical analyses : one hermaphrodite produces 300 isogenic embryos & Fay and Gerow, 2013 \\
\hline Analysis level & $\begin{array}{l}\text { Tissue and behavioural phenotypes } \\
\text { Physiology } \\
\text { Cellular (single cell level and precise cell identification) } \\
\text { Molecular }\end{array}$ & $\begin{array}{l}\text { Huang and Sternberg, 2006; } \\
\text { Yochem, } 2006\end{array}$ \\
\hline Genetics tools & $\begin{array}{l}\text { Powerful genetic analysis, a library of loss- or gain-of-function mutants } \\
\text { Amenable to forward and reverse systematic genetic screens }\end{array}$ & Ahringer, 2006; Fay, 2013 \\
\hline Biotechnology available & $\begin{array}{l}\text { Imaging at single cell level } \\
\text { Protein and mRNA traceability } \\
\text { Transgenic animals, fluorescent reporters, CRISPR-assisted genome editing } \\
\text { RNAi } \\
\text { "Omic" approaches developed }\end{array}$ & $\begin{array}{l}\text { Ahringer, 2006; } \\
\text { Dickinson and Goldstein, 2016; Kerr, } 2006\end{array}$ \\
\hline Drug testing & $\begin{array}{l}\text { Simple } \\
\text { Automatised }\end{array}$ & Hunt, 2017; O'Reilly et al., 2014 \\
\hline
\end{tabular}

Morrison et al., 2010; Tanaka and Reddien, 2011). Regenerating fish fin cells were also found to be lineage-restricted using similar cell-tracing methods (Jopling et al., 2011).

Thus, different mechanisms can lead to regeneration of the same tissue in closely related species suggesting that regeneration can be achieved via multiple paths (Simon and Tanaka, 2013). Even in a given species, not one, but a mosaic of regenerative mechanisms has been observed, depending on the tissue examined. The initial controversies have therefore begun to be solved in recent years, and in-depth examination of these phenomena have further pointed to the influence of the injury type or its extent, on the regenerative cellular mechanism at play. For instance, natural regeneration of the liver is thought to occur mainly via induced cell division and hepatocytes duplication following acute injury (Sadri et al., 2016). However, it was found that direct reprogramming is observed after extensive toxin-induced damage in liver, but not after partial hepatectomy, suggesting that the regenerative mechanism at play was damage-dependent (Yanger et al., 2013). Adding to this complexity, the developmental stage of the animal was also found to impact on the regenerative mechanisms, or its efficiency. When drastic diphtheria toxin-mediated pancreatic $\beta$ cells loss is induced, it is pancreatic $\alpha$ cells that transdifferentiate into $\beta$ cells in adult mice, but pancreatic $\delta$ cells in prepubescent mice (Chera et al., 2014; Thorel et al., 2010). Similarly, digital phalanx regeneration has been observed in young children but remains a challenge in human and mammal adults in general, revealing the impact of aging on mammalian regenerative capacities (Chera et al., 2014; Shieh and Cheng, 2015). Often it remains unclear how dominant one mechanism is compared to another in a given tissue. It is likely that a combination of specific intrinsic factors, produced by the cells, and extrinsic factors, in some cases from a permissive niche, impact on the regenerative mechanism deployed.

\section{Wound healing across species}

Wound healing has been described in several vertebrates from mice to salamanders, axolotls, teleost and lizards, as reviewed in Jacyniak et al., 2017). Wound healing is characterised by three main steps, 1) inflammation, 2) cell division and 3) tissue remodelling (Atala et al., 2010). This repair mechanism can be scar-less, or not, and examples of both possibilities exist in closely related lizard species (Wu et al., 2014). Differences exist between scar-free and scar-forming tissues repair such as speed, rate and organisation of collagen deposition, vascularisation of the wound bed, immune system activation, cytoskeleton re-organisation or production of reactive oxygen species (ROS), that lead to altered properties compared to the uninjured tissue (Corr et al., 2009; Ferguson and O'Kane, 2004). Better understanding the mechanisms underlying these processes could bring interesting perspectives for improving repair, and limiting scar formation, in mammals. Key questions have emerged from these studies notably the activation and the role of the immune system in healing. $C$. elegans possesses a collagen-based cuticle which can heal after physical injury. This healing process similarly involves activation of the innate immune system, notably via the production of antimicrobial peptides (AMPs), actin polymerization at the wound site and ROS production, making it a simple system in which to probe the cellular dynamics and key factors at play (Pujol et al., 2008a; Xu and Chisholm, 2014b).

This review will thus focus on how $C$. elegans has allowed to study the fundamental mechanisms underlying aspects of regeneration and wound healing. $C$. elegans is a transparent round worm roughly $1 \mathrm{~mm}$ long at adult stage. The advantages of the model are summarised in Table 1. Three chapters are developed below: in the first part, we review how a simple level of tissue repair is observed in $C$. elegans and has contributed to a better understanding of wound healing; in the second part, the principles of axon regeneration are reviewed; finally, lessons from natural cellular plasticity events, and natural transdifferentiation (Td) in particular, are reviewed in the third part.

\section{Studying innate immune system activation and cellular responses to wound healing in $C$. elegans}

When the integrity of the vertebrate skin is compromised by a wound or a pathogen, a series of coordinated events take place 
instantly allowing to repair and even entirely regenerate the skin with all its appendages (scales, fur, etc), depending on the severity of the skin breach. This includes an inflammation stage, where immune cells are recruited to the wound. In C. elegans, while no immune cells are present, the breach of the cuticle triggers the activation of the worm's innate immune response, as well as reorganization of the cell's cytoskeleton and ROS production, and subsequent healing of the wound (Pujol et al., 2008a; Taffoni and Pujol, 2015; Xu and Chisholm, 2014b). It should be noted that repair processes in the adult $C$. elegans do not involve cell proliferation, as the worm adult somatic cells are post-mitotic, nor does it involve cell migration. The differences in epidermis structures between mammals and $C$. elegans are presented in Table 2. The Fig. 1 summarises the mechanisms involved in wound healing in $C$. elegans.

\section{Wound closure by F-actin polymerization}

First, wounding the worm epidermis with a needle or laser triggers the release of internally stored epidermal $\mathrm{Ca}^{2+}$ (Xu and Chisholm, 2011). The $\mathrm{Ca}^{2+}$ spreads within the syncytial epidermis from the injured site to over $1 / 3$ of worm's length in a matter of seconds, and is required for survival after injury. The TRPM (transient receptor potential melastatin) channel GTL-2 is required for this $\mathrm{Ca}^{2+}$ release, possibly by initiating an initial influx of $\mathrm{Ca}^{2+}$ after wounding that would trigger the release of the internally stored $\mathrm{Ca}^{2+}$. The phospholipase C $\beta$ EGL- 8 and its regulatory Gaq protein EGL-30 likely act downstream of the GTL-2 channel, and are responsible for the release of $\mathrm{Ca}^{2+}$ from internal stores by acting on the IP3 receptor ITR-1 (Fig. 1) (Xu and Chisholm, 2011). Subsequently, the repair of the injury site involves a CDC-42 small GTPase and ARP2/3-

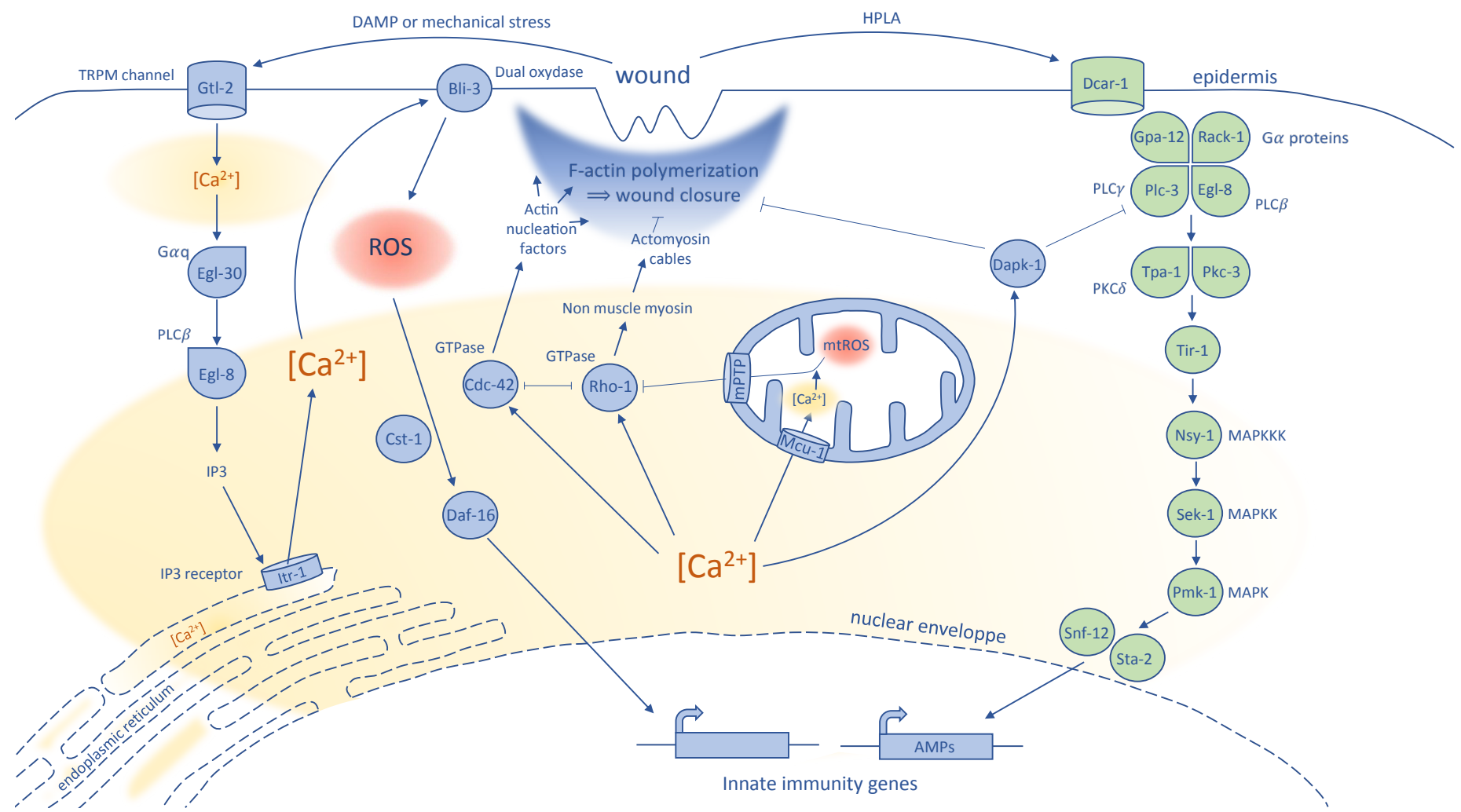

Fig. 1. Hypothetical model for the worm molecular response to epidermal wounding. Left: epidermal wounding initiates a first influx of $\mathrm{Ca}^{2+}$ within the cells through the TRPM channel Gtl-2. A subsequent molecular cascade involving the phospholipase C $\beta$ Egl-8 and its regulatory Gaq protein Egl-30 leads to the release of $\mathrm{Ca}^{2+}$ stored in the endoplasmic reticulum through the IP3 receptor Itr-1, increasing the intracellular concentration in Ca ${ }^{2+}$. The Cdc-42 GTPase could be activated by the increase in intracellular $\mathrm{Ca}^{2+}$ concentration and promotes wound closure by actin polymerization through the regulation of actin nucleation factors (Wsp-1MASP and Arx-2/Arp2/3). On the contrary, Ca2+ mediated Rho-1 GTPase activation could inhibit F-actin polymerization, either by directly inactivating $\mathrm{Cdc}-42$, or by promoting actomyosin cable formation by the intermediary of non-muscle myosin regulation. The increase in intracellular Ca ${ }^{2+}$ level also activates ROS production by the Bli-3 dual oxydase. The increase in ROS and the Cst-1/MST1 protein are responsible for the translocation of the Daf-16/FOXO transcription factor in the nucleus where it will regulate the expression of innate immunity genes. The released $\mathrm{Ca}^{2+}$ also enters the mitochondria via the mitochondrial $\mathrm{Ca}^{2+}$ uniporter $\mathrm{Mcu}-1$ and triggers the mtROS release by opening the mitochondrial permeability transition pore MPTP. The released mtROS inhibits the Rho-1 GTPase, thereby promoting the F-actin mediated wound closure. Right: Following damage to the cuticle, an increase in the HPLA ligand triggers the activation of the G-protein coupled receptor Dcar-1. The G $\alpha$ protein Gap-12 and Rack-1 and the Egl-8 and PIc-3 C-type phospholipases subsequently activate a signal transduction pathway consisting of the two protein kinases CTpa-1 and Pkc-3, the Tir-1/SARM protein, and the Pmk-1/p38 MAP kinase cascade. The Snf-12 and Sta-2 transcription factors act downstream of this pathway to activate the AMPs genes. The Dapk-1 calcium-calmodulin kinase is an inhibitor of the molecular response to epidermal wounding, acting upstream of the Tir-1/p38 signaling cascade and on the the F-actin mediated wound closure pathway. Based on Couillault et al., 2004; Dierking et al., 2011; Pujol et al., 2008a; Pujol et al., 2008b; Tong et al., 2009; Xu and Chisholm, 2011; Xu and Chisholm, 2014a; Ziegler et al., 2009; Zou et al., 2013a; Zugasti et al., 2014. 
dependent actin ring formation that progressively closes the wound within 2 hours (Xu and Chisholm, 2011). This $\mathrm{Ca}^{2+}$-triggered wound closure by local actin polymerization is reminiscent of the mechanism described for the sea urchin coelomocyte wound healing (Henson et al., 2002). In addition, actin polymerization is also seen in the formation of lamellipodia, protrusions that are necessary for the process of epithelial cell migration during epithelial wound closure in vertebrates such as zebrafish and adult mammals (Martin, 1997; Richardson et al., 2016). Another mechanism of wound closure called the "purse string" mechanism has been described, that allows, for example, the closure of Xenopus oocyte epithelial wounds at the single cell level or at the multicellular level (Clark et al., 2009) and of embryonic epithelia (Begnaud et al., 2016). This mechanism is CDC42- and RHO-dependent and uses contractile actomyosin cables. It is interesting to note that non-muscle myosin and the $\mathrm{RHO}-1$ GTPase are negative regulators of $C$. elegans epidermis wound closure (Xu and Chisholm, 2011). Therefore, actomyosin cable formation could be competing with actin polymerization in the context of the $C$. elegans epidermal wound healing, possibly underlying the mechanistic shift between a "purse string" and a lamellipodia-like powered model (Begnaud et al., 2016).

\section{Reactive oxygen species production}

ROS are produced by various cellular compartments and take part in different biological processes including wound healing (Dunnill et al., 2017). An increase in ROS was found to be produced by the mitochondria (mtROS) at the site of epidermal or laser wounding, ultimately promoting the F-actin mediated wound closure. Analysis showed that the wound-induced increase in intracellular $\mathrm{Ca}^{2+}$ level led to $\mathrm{Ca}^{2+}$ uptake by the mitochondria via the mitochondrial $\mathrm{Ca}^{2+}$ uniporter. This event triggered $\mathrm{mtROS}$ release by opening the mitochondrial permeability transition pore (mPTP). The released mtROS, mostly superoxide, then directly inhibited the redox-sensitive motif of the RHO-1 GTPase, thereby reducing $\mathrm{RHO}-1$ wound closure inhibition activity (Fig. 1) (Xu and Chisholm, 2014a). This study implicated for the first time the mitochondria in the process of wound signalling. The relevance of these pathways for mammalian epithelial wound repair needs now to be assessed. As a start, it has recently been shown that a $\mathrm{Ca}^{2+}$-triggered increase in mtROS production facilitates actin-mediated wound closure of injured skeletal muscle cells in mice (Horn et al., 2017).

\section{Production of antimicrobial peptides (AMPs)}

C. elegansdoesn't possess specialized immune cells per se, but injury and bacterial or fungal infections induce an innate immune response that includes the production of antimicrobial peptides (AMPs), especially, in the case of fungal infection of the epidermis, members of the NLP (neuropeptide-like protein) and the CNC (caenacin) families (Engelmann and Pujol, 2010). While some AMPs are evolutionarily conserved (Braff et al., 2005; Mangoni et al., 2016; Pujol et al., 2008b), others show extensive lineage-specific diversification (Pujol et al., 2012). Different pathways, partially convergent, have been shown to be necessary for the increased production of the AMPs in the epidermis and are detailed below.

The nlp-29 and nlp-31 AMP genes are up-regulated in the worm epidermis following damage to the cuticle, either by physical wounding during a laboratory procedure or during a fungal infection involving piercing of the epidermis by the pathogen (Pujol et al., 2008a). For production of these NLPs during wounding, the G-protein coupled receptor DCAR-1 (DihydroCaffeic Acid Receptor) is first activated by the endogenous ligand HPLA (4-hydroxyphenyllactic acid, a tyrosine-derivative) (Zugasti et al., 2014). This activates the G $\alpha$ protein GPA-12 and RACK-1 and the PLC-3 C-type phospholipase that act upstream of two proteins kinases C:TPA-1 and PKC-3 (Fig. 1) (Ziegler et al., 2009; Zugasti et al., 2014). The signal transduction then requires the TIR (TOLL-interleukin 1 receptor) domain protein, TIR-1, orthologue of the human SARM (sterile $\alpha$ and armadillo motifs) that activates a p38 MAP kinase cascade (Couillault et al., 2004; Pujol et al., 2008a; Pujol et al., 2008b). The sodium-neurotransmitter symporter SNF-12 and its interac-

TABLE 2

\section{COMPARING EPIDERMIS STRUCTURE AND WOUND HEALING SIMPLE FEATURES IN $C$. ELEGANS AND MAMMALS}

\begin{tabular}{|c|c|c|c|}
\hline Feature & Mammals & C. elegans & References \\
\hline Epidermis structure & $\begin{array}{l}\text { Self-renewing stratified tissue: epidermis and dermis separated by the } \\
\text { basal membrane }\end{array}$ & $\begin{array}{l}\text { Single epithelial layer composed by the assembly of several } \\
\text { postmitotic syncytia, the main one being hyp } 7\end{array}$ & Matejuk, 2017 \\
\hline Extracellular matrix & Extracellular matrix produced by fibroblasts & $\begin{array}{l}\text { Apical surface of polarized epithelium, golgi bodies secrete cuticle: } \\
\text { three different types of collagenous layers }\end{array}$ & Matejuk, 2017 \\
\hline Irrigation & Lymphatic and blood vessels & None & Matejuk, 2017 \\
\hline Immunity & $\begin{array}{l}\text { Neutrophils differentiating into macrophages } \\
\text { Resident immune cells }\end{array}$ & $\begin{array}{l}\text { Innate immune response:, no macrophages, no cell migration } \\
\text { ROS production } \\
\text { AMPs production }\end{array}$ & $\begin{array}{l}\text { Chisholm and Xu, 2012; } \\
\text { Matejuk, 2017; } \\
\text { Xu et al., } 2012\end{array}$ \\
\hline Key steps after wound & $\begin{array}{l}\text { 1) wound } \\
\text { 2) blood clot formation } \\
\text { 3) inflammation } \\
\text { 4) repair/ angiogenesis }\end{array}$ & $\begin{array}{l}\text { 1) wound } \\
\text { 2) closure } \\
\text { 3) repair: cuticle synthesis }\end{array}$ & Takeuchi and Akira, 2010 \\
\hline Deep wound: & $\begin{array}{l}\text { Fibroblasts migrate to the wound, proliferate: formation of extracellular } \\
\text { matrix (fibronectin and collagen). }\end{array}$ & $\begin{array}{l}\text { Needle insult: } 3 \text { hrs closure } \\
\text { Laser insult: } 24 \text { hrs closure }\end{array}$ & Sasaki et al., 2008 \\
\hline Closure & Contractile myofibroblasts & Actin polymerisation & $\begin{array}{l}\text { Begnaud et al., 2016; } \\
\text { Xu and Chisholm, } 2011\end{array}$ \\
\hline Transdifferentiation & $\begin{array}{l}\text { Mesenchymal stem cell Td into keratinocytes, endothelial cells and } \\
\text { pericytes fibroblasts. } \\
\text { Murine myofibroblasts reprogram in vivo into adipocytes cells }\end{array}$ & & Plikus et al., 2017 \\
\hline Stem cells & Long-term epidermal stem cells of basal layer increase their activity & & $\begin{array}{l}\text { Mascre et al., 2012; } \\
\text { Eming et al., } 2014\end{array}$ \\
\hline Dedifferentiation & Sebaceous duct lineage dedifferentiates into stem cell & & \\
\hline Scar & $\begin{array}{l}\text { Remodelling of the new extracellular matrix leaves a scar composed of } \\
\text { ECM filaments }\end{array}$ & & Midwood et al., 2004 \\
\hline
\end{tabular}


tor the STA-2 transcription factor like protein have been shown to act downstream of the p38 MAPK pathway (Fig. 1; Dierking et al., 2011). Injury also induces the expression of $c n c$ genes, especially a subgroup constituted of $c n c-1, c n c-5$ and $c n c-11$ partially via the p38 MAP kinase pathway (Zugasti and Ewbank, 2009).

Sterile wounding also induces AMPs production in worms and mammals (Pujol et al., 2008a; Sorensen et al., 2006). Additional roles of the AMPs in wound healing have been described in mammalian and non-mammalian model systems, for example in the stimulation of collagen synthesis or the inactivation of bacteria LPS (lipopolysacchararide) which reduces inflammation (Mangoni et al., 2016). AMP production occurs normally in mutants with defects in $\mathrm{Ca}^{2+}$ signalling, but is negatively regulated by the DeathAssociated Protein Kinase DAPK-1 (Xu and Chisholm, 2011; Tong et al., 2009). This DAPK-1 calcium-calmodulin kinase is a negative regulator of the innate immune response, acting upstream of the TIR-1/p38 signalling cascade; upregulation of several epidermalAMP genes is observed in a dapk-1 mutant (Tong et al., 2009). DAPK-1 also negatively regulates the wound closure pathway (Xu and Chisholm, 2011). Therefore, DAPK-1 seems to be a general repressor of the epidermal wound healing process in $C$. elegans. Mutants for the nematode-specific gene sydn-1 suppress the morphological phenotypes of dapk-1, without affecting the elevated AMP gene expression provoked by loss of dapk-1 (Tong et al., 2009). dapk-1 also genetically interacts with patronin (PTRN-1), a regulator of microtubule stability that can antagonise DAPK-1 in the process of wound closure, and, in contrast to SYDN-1 is required for the elevated AMP gene expression seen in dapk-1 mutants (Chuang et al., 2016). Interestingly, the homolog of DAPK-1 in mammals (DAPK) is also implicated in the immune response, with several roles in the regulation of the inflammatory response (Lai and Chen, 2014). Study of the DAPK-1 family in C. elegans is expected to provide insights on the necessary control of the coordinated responses to injury.

Fig. 2. Growth cone formation, axon fusion and key signalling pathways for axon regeneration. (A) Injury first causes release of calcium ( $\left.\mathrm{Ca}^{2+}\right)$ via 1) membrane release (orange), 2) voltage-gated calcium channel opening (EGL-19 (VGCC a1)) causing a bidirectional membrane propagation (orange arrow) of $\mathrm{Ca}^{2+}$ (blue), 3) Activation of $\mathrm{Ca}^{2+}$-dependent $\mathrm{Ca}^{2+}$ release from internal storages leading to transient $\mathrm{Ca}^{2+}$ waves (blue). $\mathrm{Ca}^{2+}$ dependent activation of CAMP and DLK-1 regeneration-dependent pathway lead to three key steps of axon regeneration: 1) growth cone formation, 2) axon extension and guidance and 3) fusion to target when it occurs. (B) Growth cone formation: Increased calcium levels activate 1) production of CAMP and activation of the PKA pathway, 2) the DLK-1 pathway which is also activated by microtubule (MT) disruption after injury. MT-associated proteins, such as the N-terminal EFA-6 factor, polymerisation and depolymerisation factors such as the depolymerizing kinesin-13 family member KLP-7 factor, act downstream DLK-1 whereas the tubulin posttranslational modifiers Patronin PTRN-acts in parallel. The Notch/lin-12 signalling prevents growth cone formation in a cellular-autonomous and DLK-1 independent manner (El Bejjani and Hammarlund, 2012). Ca ${ }^{2+}$-dependent activation of apoptotic factors CED3 and CED4 allows maintenance of the distal fragment, via DLK-1 (Pinan-Lucarre et al., 2012). (C) Injury triggers relocalisation of key proteins from soma to injured membranes for axon fusion. After injury, 1) u61569 PSR-1 relocalises from mitochondria and nuclei to axon tip (yellow dotted arrow) and axotomy-triggered flipping of the phosphatidylserine lipid (PS) (blue square). TTR-52 (red circle) relocates from PLM axonal soma to both the distal and proximal membrane (red dotted arrow) and could bind exposed PS for fusion. u61570 epithelial fusion failure-1 EFF-1 (green) relocalises from soma to distal tip of the severed membranes (green doted arrow) after injury. PSR-1/PS binding and relocalisation of the secreted PS binding protein TTR-52/transthyretin allowed the recruitment of u61571 apoptotic clearance molecules (NRF-5, CED-7, or CED-6) which are required upstream of EFF-1 for 2) the EFF-1 dependent fusion process of both axonal ends.

\section{Conclusion and perspectives, wound healing studies in C. elegans}

Even though there are differences between the mammalian and $C$. elegans models, like the skin structure and the presence in mammals of cellular immunity, it is now clear that most of the lecular players and the main pathways are conserved. Using elegans model, the early role of the $\mathrm{Ca}^{2+}$ release in healing has been shown at the organismal level for the first time.
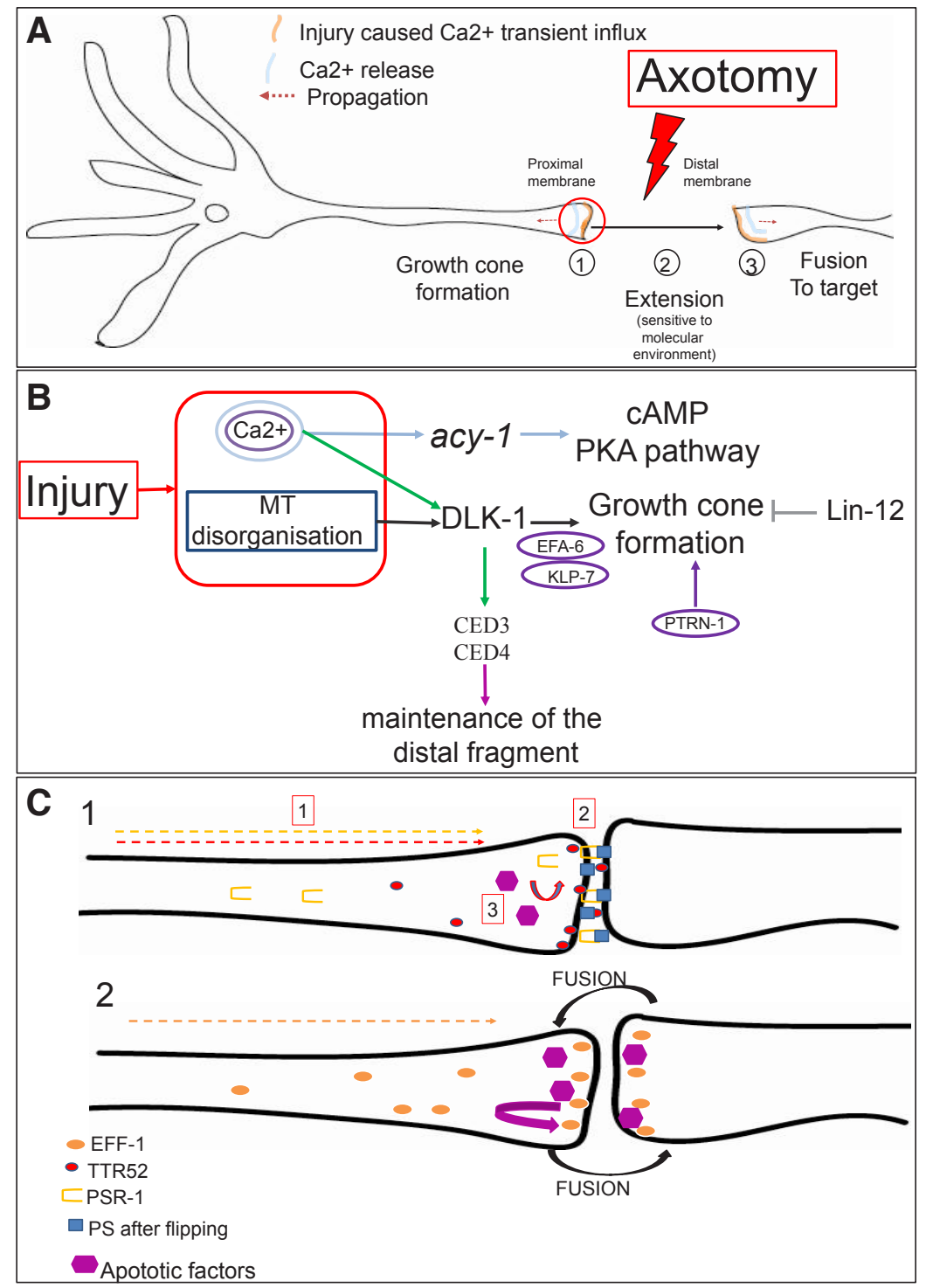
this first $\mathrm{Ca}^{2+}$ wave, namely GTL-2 (see above). A key aspect to elucidate in the future is to understand how the initial wounding signal is sensed. Mechanical properties of the damaged area during wounding are probably altered (Taffoni and Pujol, 2015; Dodd et al., 2018), and these could conceivably be sensed by TRPM channels and initiate the $\mathrm{Ca}^{2+}$ release (Enyedi and Niethammer, 2015). This hypothesis remains to be tested and the worm would be a suitable model for such studies, which could then be extended to the mammalian epithelial TRP channels. The studies described above in the worm model have also shed light on the molecular pathways involved in ROS production during wound healing, in particular a newly described $\mathrm{Ca}^{2+}$-mediated burst in mtROS. It highlighted the beneficial consequences of ROS production on the regulation of innate immunity gene expression and actin-mediated wound closure at the protein level.

It is interesting to note that the majority of the proteins found to be involved in the response to injury in $C$. elegans have mammalian counterparts that are suspected to be involved in wound healing as well. Considering the complexity of the epithelial wound repair response in mammalians, $C$. elegans proves to be an interesting model system in which individual components of the epithelial wound response can be teased apart and their interactions analysed. The elucidation of these pathways might lead to improved therapies for wound treatment.

\section{Axotomy reveals the cellular dynamics and the molecu- lar aspects of axon regeneration in C. elegans}

In mammals, axons of the central nervous system (CNS) regenerate poorly, whereas neurites of the peripheral nervous system (PNS) show better regenerative capacities (Chen et al., 2007). Why can axons in the PNS but not in the CNS regrow? Using models to study extrinsic and intrinsic factors crucial for axon regeneration is essential to answer this question.

The simplicity as well as the cellular and synaptic predetermination of the nervous system in $C$. elegans is a key advantage for axon regeneration's study. Hermaphrodites have 302 nerve cells and males have 385 neurons (www.wormatlas.org; White et al., 1986). Fifty-six glial-like cells are also observed, they are essential for axon guidance and good neuronal connectivity; however, axons are not myelinised in C. elegans (Oikonomou and Shaham, 2011). C. elegans neurons have unipolar or bipolar axon trajectories and can form synapses « en passant » meaning that cells can connect elsewhere than at the axon end, along the neurite or close to the cell body (Hobert, 2013). C. elegans produces all the main neurostransmitters found in mammals including acetylcholine, glutamate, $\gamma$-amino butyric acid (GABA), dopamine, and serotonin as well as their receptors (Hobert, 2013).

In 2004, Yanik et al.,2004), developed a technique of femtosecond laser surgery in $C$. elegans for laser axotomy of single axons. Axon regrowth generally occurs within 6 to $24 \mathrm{hrs}$ (Wu et al., 2007; Yanik et al., 2004). The combination of laser axotomy, with accurate single cell fluorescent marking, powerful genetics and phenotype analysis such as restoration of locomotion, have made of $C$. elegans an extremely powerful model to test axon regeneration molecularly and functionally at the single axon level. Another non-invasive method of axon severing has taken advantage of mutants in the $\beta$-spectrin coding gene unc- 70 that cause a movement-induced breaking of axons in newly hatched larvae which triggers regeneration before the adult stage (Hammarlund et al., 2007).

\section{Localisation of injury, age, as well as the neuron type are parameters that can influence efficiency and functional axon regeneration in $\mathrm{C}$. elegans}

Not all neurons have regenerative abilities in $C$. elegans but when they do, the process of axon regeneration per se is characterised by an error-prone regrowth as in mammals. Axons of the GABAergic neurons extend from the ventral side to the dorsal side of the worm, they are usually severed at a lateral point of the commissures to test regrowth dorsally (Yanik et al., 2004). Regrowth has been studied after laser axotomy or in the $\beta$-spectrin fragile axon model such as in Hammarlund et al., 2007. Results are not directly comparable but together they show that regrowth is observed in around $70 \%$ of the injured GABAergic neurons (Hammarlund et al., 2007; Wu et al., 2007; Yanik et al., 2004), but only $10 \%$ reconnect with dorsal side and re-establish motor functions (Byrne and Hammarlund, 2017; Wu et al., 2007). Gabel et al., (2008) also observed different rates of successful regrowth for the mechanosensory neurons, depending on the localisation of the damage (Gabel et al., 2008). The bilaterally symmetric pair of posterior and anterior lateral touch neurons, PLM and ALM, have one long (300 $\mu \mathrm{m}$ in L4) and large axon that can be imaged in one focal plan which is a great advantage for dynamic imaging. The axon regrew when the laser surgery was performed proximal to the collateral synaptic branch whereas it did not regrow when the axon was injured distally to the branch point. Removal of the distal axon allowed regrowth suggesting that the synaptic branch point may be a sensor and a regulator with a positive or a negative effect on regrowth (Gabel et al., 2008). Age was also found to diminish axon regenerative capacities (Gabel et al., 2008).

Globally, axon regeneration follows the same dynamics in $C$. elegans as in mammals (Fig. 2A). Below, we examine the recent advances of axonal regeneration in C. elegans: microtubule (MT) dynamics, axon fusion and key signalling pathways.

\section{Injury-dependent disruption of microtubules and calcium transient release activate the DLK-1 and cAMP pathways required for axon regeneration in $\mathrm{C}$. elegans}

Axotomy disrupts the cell morphology by interrupting the cell plasma membrane and cutting the axon in two parts. What are the cellular consequences of this insult? The injury-dependent disruption and changes in regulation of the cytoskeleton's dynamic is a pivotal parameter of axon regeneration cellular's response notably via formation of an injury-dependent structure at the bulge of the distal axon, the growth cone. MT are architects of growth cone formation and their role in axon regeneration in $C$. elegans is reviewed in Chisholm (2013). In addition, MT disruption is interpreted as a cellular signal for activation of signalling pathways. The importance of MT's dynamics for axon regeneration has been highlighted by the identification in $C$. elegans of several mutants encoding inhibitors and activators of MT's dynamics. Three MT dependent phases can be described for regeneration: 1) An injury-dependent increase of MT depolymerisation/polymerisation resulting in injury-dependent activation of signalling pathways. 2) Remodelling of the cytoskeleton associated with reduction of MT catastrophes which allows growth cone to build up. 3) Axon extension; at this final stage, stabilisation of assembled MT does 
not appear to prevent regeneration.

What are the signals triggered by axon severing? Several forward and reverse RNAi genetic screens have been performed to identify candidate activators and inhibitors of axon regeneration in C. elegans (Chisholm et al., 2016; Hisamoto and Matsumoto, 2017; Nix et al., 2014; Nix et al., 2011) and the main factors are reviewed in Hisamoto and Matsumoto (2017). Calcium transient influx is a conserved key first signal triggered by injury, as revealed by the use of genetically encoded $\mathrm{Ca}^{2+}$ sensors. This calcium transient increase, associated to IP3 increase, activates cAMP/ PKA and the conserved DLK-1 regenerative pathways. Altogether these signalling pathways play multiple roles, ensuring remodelling and regulation of microtubule's dynamics for growth cone formation and extension. The process of growth cone formation and the inter-regulation within these pathways in $C$. elegans is summarised on Fig. 2B. Many of the key players and steps of axon regeneration are similar in $C$. elegans and mammals (mouse or rat), and Table 3 compares their role in the two species (GhoshRoy et al., 2012; Ghosh-Roy et al., 2010; Tang and Chisholm, 2016; Yan et al., 2009).

Fusion to the distal fragment allows robust functional regeneration. In $C$. elegans, the distal fragment of mechanosensory neurons, named ALM and PLM, can fuse with the growing axon in a process that is also promoted by calcium and CAMP (Ghosh-Roy et al., 2010; Neumann et al., 2015). Axotomy causes relocalisation of proteins at the distal and proximal membranes for fusion, as summarised in Fig. 2C (Neumann et al., 2015). Oren-Suissa et al., (2017) showed that the secreted factor AFF-1 mediates

A

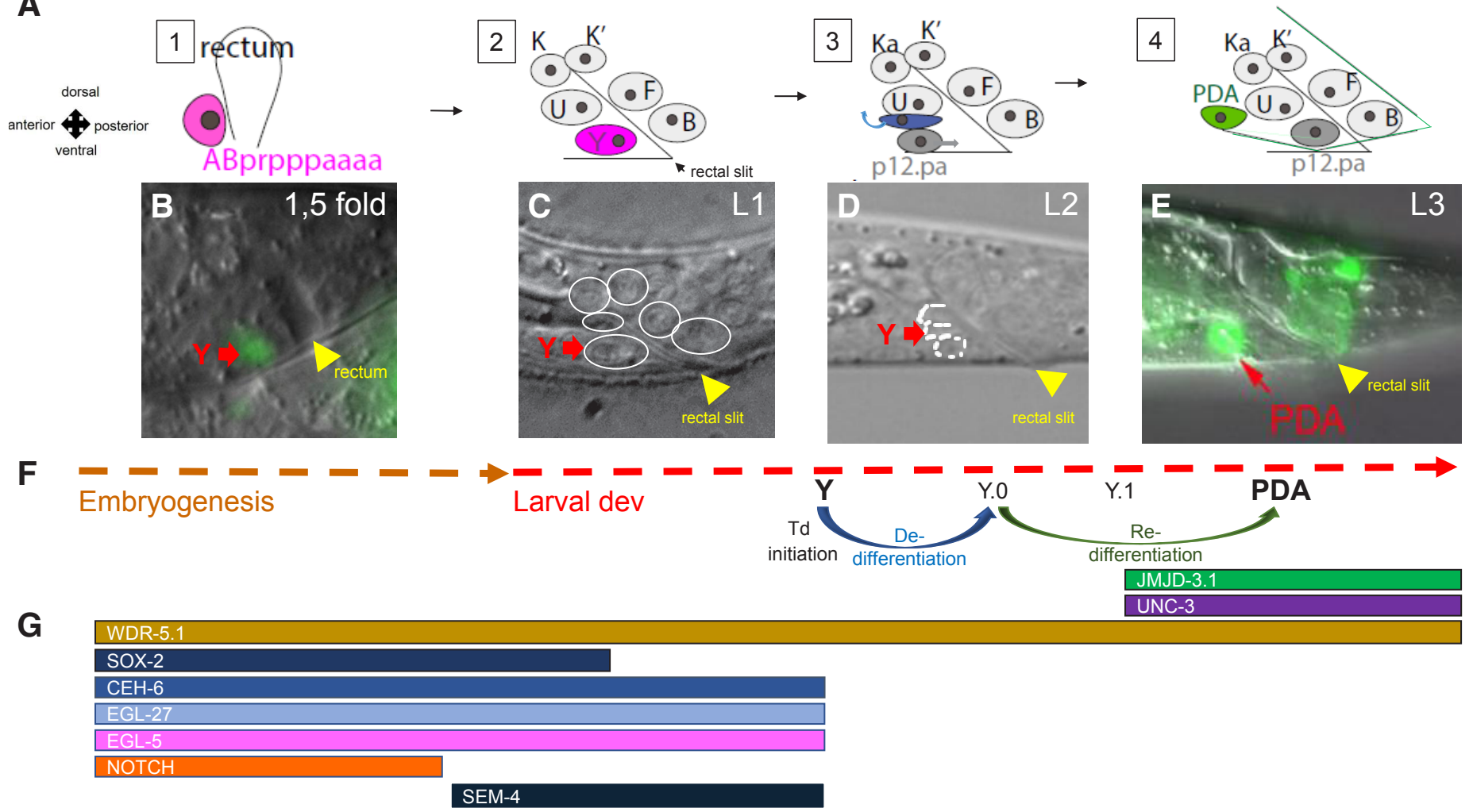

Fig. 3.Time course of Y-to-PDA transdifferentiation and dynamic expression of some key factors throughout the process. (A) Schematics showing cellular dynamics during transdifferentiation. (1) Focus on the rectum at the embryonic 1.5-fold stage showing the position with respect to the rectum of ABprpppaaaa (purple), which becomes the rectalY cell; this cell is born at 290 minutes after fertilisation (Horvitz and Sulston, 1983). (2) The rectum in early L 1 larva, composed of the six rectal cells known as: $Y$ (purple), B, U, F, K and $K$. The rectal slit is the visualisation of the lumen. (3) Transdifferentiation initiation starts at the end of the L1 stage, Y migrates anteriorly and dorsally (purple arrow) whereas a cell named P12.pa replaces $Y$ in the rectum (dark grey cell, grey arrow for migration). (4) In the L3 larval stage, the PDA motoneuron (green cell) with its characteristic axon is observed and P12. pa has replaced $Y$ in the rectum. (B-E) Microscope images of embryos and blow ups of the rectum area throughout transdifferentiation. (B) Blow up of the rectal area of a 1.5-fold embryo expressing a Y-specific marker (green cell, red arrow). (C) DIC picture of the rectal area of an early $L 1$ larva before the initiation of transdifferentiation; the nuclei of the six rectal cells are circled in white, and the Y cell is indicated by a red arrow. (D) $L 2$ larva, ventral to dorsal: the P12.pa, migrating Y (red arrow) and U nuclei are circled in white. (E) L3 transgenic larva expressing GFP in the PDA motoneuron (green cell, red arrow - adapted from Richard et al., 2011). The yellow arrows show the rectum in embryos or the rectal slit in larval stages; anterior is to the left and ventral to the bottom. (F) Timeline of transdifferentiation. At the end of the L 1 larval stage, epithelial markers are lost and Y dedifferentiates (blue arrow) to becomes a unipotent transient cell, Y.O. Then, Y.O redifferentiates step-wise into the PDA motoneuron, first by becoming an early neural cell Y.1. (G) Molecular players. Shortly after $Y$ birth in the embryo, lin-12/Notch, ceh-6/OCT, egl-27/MTA1, sox-2, egl-5/HOX are expressed and required in the $Y$ cell to promote its dedifferentiation; the LIN-12/NOTCH receptor is activated and is required until embryonic 2.2-fold for $Y$ formation and transdifferentiation and sem-4/SALL4 is expressed from the embryonic 3-fold stage on (Kagias et al., 2012; T. Daniele \& S. Jarriault personal communication). Redifferentiation requires the UNC-3/EBF transcription factor and the histone modifier JMJD-3.1. Perfect efficiency and robustness of the process is ensured via step-wise histone modifications involving H3K4 and H3K27 methylation (see WDR-5.1, JMJD-3.1, Zuryn et al., 2014). 
dendrite fusion with the epithelial fusion failure 1 (EFF-1) in cell non-autonomous manner (Oren-Suissa et al., 2017).

\section{Understanding the effects of environment and developmental stage on axon regeneration}

Diverse parameters can influence and reduce axon regeneration capacities. In $C$. elegans, the role of the niche, of stress and age have been investigated and progresses are described below.

What are the key pro-regenerative molecular features setting a permissive environment for axon regeneration? Chen et al., 2007 recapitulates the factors favouring regrow in mammals. Notably, in the PNS, macrophages and Schwann cells clear the fragment debris permitting the establishment of a permissive regenerative environment (Chen et al., 2007). The favourable niche for axon regrowth is also a combination of attractant and repellent molecules which allow axon guidance during axon extension. A number of them have been identified in $C$. elegans. svh-1 and svh-2 genes encode a growth factor and its receptor tyrosine kinase (RTK) respectively. SVH-1 is secreted from a pair of ADL sensory neurons in the head and acts on its receptor SVH-2 present in motor neurons and mechanosensory neurons to promote axon regrowth ( $\mathrm{Li}$ et al., 2012). In addition, Gabel et al., (2008) elucidate the combined action of SLT-1/slit, which is secreted by dorsal muscle and acts as a repellent molecule, whereas UNC-6/netrin expressed by the axons acts as an attractant molecule, on AVM axon trajectories after laser surgery. Mutations in the netrin or SLT-1 led to 30-40\% defects in AVM ventral guidance, whereas mutations in both resulted in $90 \%$ defects (Hao et al., 2001). Finally, Torpe et al., 2017 observed guidance defects in ret-1 mutants. ret-1 codes for the sole $C$. elegans member of the Nogo-A family. These defects

TABLE 3

COMPARISON OF KEY FACTORS AND SIGNALLINGS DURING AXON REGENERATION IN C. ELEGANS AND MAMMALS

\begin{tabular}{|c|c|c|c|}
\hline Molecules & C. elegans & Mammals & References \\
\hline \multicolumn{4}{|l|}{ Calcium } \\
\hline First signal & $\begin{array}{l}\text { First signal induced by injury via activation of the voltage-gated } \\
\mathrm{Ca}^{2+} \text { channel current (EGL-19) }\end{array}$ & $\begin{array}{l}\text { Activation of the L-type voltage-gated } \mathrm{Ca}^{2+} \text { channel current triggers } \\
\text { transcriptional changes promoting regrowth }\end{array}$ & $\begin{array}{l}\text { Ghosh-Roy et al., 2010; } \\
\text { Enes et al., } 2010\end{array}$ \\
\hline Downstream effects & Downstream effects on growth cone formation & Control of growth cone formation & \\
\hline \multicolumn{4}{|l|}{ CAMP } \\
\hline $\mathrm{Ca}^{2+}$ dependence & $\begin{array}{l}\text { Activated by } \mathrm{Ca}^{2+} \text { transient increase and activation of specific } \\
\text { adenyl cyclase }\end{array}$ & $\mathrm{Ca}^{2+}$ dependent increase & $\begin{array}{l}\text { Ghosh-Roy et al., 2010; } \\
\text { Park et al., 2004; } \\
\text { Neumann et al., 2002; } \\
\text { Spencer and Filbin, } 2004\end{array}$ \\
\hline $\mathrm{Ca}^{2+}$ independent & Enhances axon regeneration & $\begin{array}{l}\text { Enhances regeneration in rat sciatic nerve, in CNS and central branch of } \\
\text { DRGs in presence of the myelin-associated inhibitors in vivo }\end{array}$ & \\
\hline \multicolumn{4}{|l|}{ PKA } \\
\hline $\begin{array}{l}\text { Related to } \mathrm{Ca}^{2+} \text { for } \\
\text { regeneration }\end{array}$ & $\begin{array}{l}\text { Promotes axonal regrowth, reconnection of distal and proximal } \\
\text { axonal fragments, formation of branches to the target region }\end{array}$ & $\begin{array}{l}\text { Regulation of cytoskeleton organization, inhibits Rho dependent inhibitory } \\
\text { effects of myelin associated glycoprotein on regeneration }\end{array}$ & $\begin{array}{l}\text { Ghosh-Roy et al., 2010; } \\
\text { Snider et al., } 2002\end{array}$ \\
\hline \multicolumn{4}{|l|}{ DLK-1 } \\
\hline $\begin{array}{l}\text { Key for axon } \\
\text { regeneration }\end{array}$ & $\begin{array}{l}\text { Promotes regrowth of } C \text {. elegans touch neurons and motor } \\
\text { neurons }\end{array}$ & Promotes DRG neuron regrowth in culture & Hammarlund et al., 2009; \\
\hline $\begin{array}{l}\text { Involved in injury- } \\
\text { dependent cytoskeleton } \\
\text { remodelling }\end{array}$ & $\begin{array}{l}\text { Activates microtubule dynamics for growth cone formation } \\
\text { Crosstalks between the DLK-1 and the MLK-type MLK-1/KGB-1 } \\
\text { JNK }\end{array}$ & $\begin{array}{l}\text { Enhances an axonal retrograde injury signal (involving cytoskeleton) in } \\
\text { peripheral nerves }\end{array}$ & $\begin{array}{l}\text { Yan et al., 2009; } \\
\text { Itoh et al., 2009; } \\
\text { Shin et al., 2012; }\end{array}$ \\
\hline & $\begin{array}{l}\text { A mammalian DLK homolog rescues } C \text {. elegans axon } \\
\text { regeneration in dlk-1 mutants in vivo }\end{array}$ & Activates c-JUN in DRG & \\
\hline \multicolumn{4}{|c|}{ DLK- 1 independent pathway } \\
\hline $\begin{array}{l}\text { Alternative regenerative } \\
\text { pathway related }\end{array}$ & $\begin{array}{l}\text { ASJ neurons: Triggered by reduced neuronal activity and } \\
\text { improved by calcium and cAMP } \\
\text { Activation of SAX-1/NDR kinase or UNC- } 43 / \text { CaMKII }\end{array}$ & Repair in DRG in CNS ranch after « lesion-conditioning » & $\begin{array}{l}\text { Chung et al., 2016; } \\
\text { Enes et al., } 2010\end{array}$ \\
\hline \multicolumn{4}{|l|}{ DAF-18/PTEN mTOR } \\
\hline $\begin{array}{l}\text { Negative regulator of } \\
\text { regeneration }\end{array}$ & $\begin{array}{l}\text { DAF-18/PTEN negatively regulates GABA motor neuron axon } \\
\text { regeneration. PTEN's function might be mediated via mTOR }\end{array}$ & $\begin{array}{l}\text { PTEN is a negative mediator of axon regeneration of retinal ganglion cells, } \\
\text { peripheral sensory (sciatic) neurons, corticospinal neurons via inhibition of } \\
\text { mTOR }\end{array}$ & $\begin{array}{l}\text { Byrne et al., 2014; } \\
\text { Liu et al., 2010; } \\
\text { Park et al., } 2008\end{array}$ \\
\hline \multicolumn{4}{|l|}{ Daf-16/FOXO } \\
\hline $\begin{array}{l}\text { Insulin pathway affects } \\
\text { regeneration }\end{array}$ & $\begin{array}{l}\text { DAF-2 (insulin receptor) dependent activation of DAF-16 } \\
\text { regulates age-dependent inhibition of GABA motor neuron axon } \\
\text { regeneration in parallel or upstream of DLK-1 pathway }\end{array}$ & $\begin{array}{l}\text { IGF-1 (insulin growth factor) stimulates injured segment of rat sciatic nerve } \\
\text { regeneration }\end{array}$ & $\begin{array}{l}\text { Byrne et al., 2014; } \\
\text { Sjoberg and Kanje, } 1989\end{array}$ \\
\hline \multicolumn{4}{|l|}{ EFA-6 } \\
\hline $\begin{array}{l}\text { Microtubule-associated } \\
\text { protein negatively } \\
\text { regulating regeneration }\end{array}$ & $\begin{array}{l}\text { Involved in MT dynamics } \\
\text { Inhibition of regeneration }\end{array}$ & EFA6A, C, D expressed in neurons & $\begin{array}{l}\text { Chen et al., 2011; } \\
\text { Chen et al., 2015; } \\
\text { Sakagami et al., } 2006\end{array}$ \\
\hline \multicolumn{4}{|l|}{ PATRONIN-1 } \\
\hline $\begin{array}{l}\text { Microtubule associated } \\
\text { protein promoting } \\
\text { regeneration }\end{array}$ & Required for axon regrowth, modulating MT dynamics & $\begin{array}{l}\text { Of the three mammalian CAMSAPs, CAMSAP2 is important for axon } \\
\text { specification, dendrite morphology in mouse hippocampal neurons }\end{array}$ & $\begin{array}{l}\text { Chuang et al., 2014; } \\
\text { Yau et al., } 2014\end{array}$ \\
\hline \multicolumn{4}{|l|}{ Nogo-A/Ret-1 } \\
\hline $\begin{array}{l}\text { Molecule of the niche } \\
\text { negatively influencing } \\
\text { axon regrow }\end{array}$ & Inhibition of sensitivity to Ephrin & Neurite inhibitory protein & $\begin{array}{l}\text { Torpe et al., 2017; } \\
\text { Freund et al., } 2006\end{array}$ \\
\hline \multicolumn{4}{|l|}{ HIF-1 } \\
\hline $\begin{array}{l}\text { Stress pathway } \\
\text { activated after injury } \\
\text { for axon regrow }\end{array}$ & $\begin{array}{l}\text { Axotomy in GABAergic D (non-serotonergic) neurons caused } \\
\text { activation of hypoxia-inducible (HIF); this activates tph-1 } \\
\text { (tryptophan hydrolase) expression and transient synthesis of } \\
\text { serotonin which activates pro-regenerative pathways }\end{array}$ & $\begin{array}{l}\text { Injury dependent activation of hypoxia-inducible (HIF) expression and } \\
\text { targets } \\
\text { Increased after spinal cord injury, increases protein stability and activates } \\
\text { HIF-1 } \alpha \text { target genes }\end{array}$ & $\begin{array}{l}\text { Alam et al., 2016; } \\
\text { Xiaowei et al., } 2006\end{array}$ \\
\hline
\end{tabular}


depended on the activity of the ephrin ligand VAB-2 via the Eph receptor VAB-1 (Torpe et al., 2017). RET-1 appears to be involved in setting a « non-ephrin responsive » environment as in mammals, via a yet to be elucidated mechanism (Torpe et al., 2017).

Could axotomy/injury dependent axon regeneration activate a sum of stress-dependent pathways? Work in $C$. elegans highlighted a role for the stress Hypoxia induced (HIF) pathway, as found in spinal cord injury, and further studies identified relevant targets of HIF-1 in this context and showed that the HIF1 pathway is differentially used depending on the neuronal type (Alam et al., 2016). The current understanding of HIF-1 involvement in axon regeneration is summarised in Table 3 . In addition, $C$. elegans studies suggested a role for genes ensuring mitochondrial functions, such as eat-3/Opa1, and of iron-sulfur proteins such as ISP-1. Interestingly, ISP-1 could act downstream of DLK-1 and $\mathrm{Ca}^{2+}$ for axon extension (Knowlton et al., 2017). Finally, while increased protein synthesis is also observed during regeneration, the metabolic variations triggered by injury remain poorly explored and may be the focus of future investigations. Better characterising the injury-dependent molecular pathways related to stress as well as their cellular outcomes for axon regeneration is an interesting perspective that can be pursued in $C$. elegans.

What happens with age? Axon regeneration has been observed to decrease both in mammals and in C. elegans (Byrne et al., 2014; Gabel et al., 2008; Hammarlund et al., 2009; Nix et al., 2011; Verdfi et al., 1995; Wu et al., 2007; Zou et al., 2013b). In C. elegans, age triggers a general dramatic decrease of growth response and extension and increased axon guidance errors after insult (Byrne et al., 2014; Wu et al., 2007). However, this may need to be examined at the individual neuron level, as Wu et al., (2007) established that the PLM, AVM and AWB neurites can regrow at adult stage. In the mechanosensory neurons PLM and ALM, functional regeneration efficiency is larval stage dependent. GABAergic motor neurons robustly regenerate in L1/L2 (nearly $100 \%$ ); however, in L4, even if axons initiate injury response and formation/extension of growth cone, the nerve cord is not reliably reached, and cone mobility is reduced. The levels of MLK-1 seem somewhat predictive of success, since when MLK-1 is overexpressed then growth up to $40 \%$ cone initiation (against $12 \%$ in controls) is observed in adult and initiation is more than twice faster (Nix et al., 2011). MLK-1 can initiate and accelerate cone formation in a rather non-permissive, age dependent context. Byrne et al., (2014), suggested that the insulin receptor, DAF-2, could be responsible for inhibiting aging GABA motor neuron axon regeneration (Byrne et al., 2014). They show that this effect is intracellularly mediated by the forkhead transcription factor DAF-16/FOXO, suggesting that aging effects are cell-autonomous (Byrne et al., 2014).

The impact of age is rather negative on axon regeneration and easy to assess in C. elegans. However, it remains difficult to described the molecular mechanisms behind the changes caused by age. Altogether, more work in $C$. elegans could help progresses in deciphering how the niche, stress and age affect axon regeneration.

\section{Cellular plasticity in C. elegans}

During regeneration, cells undergo several transformations, at the morphological, physiological, transcriptional and translational levels, and they can also migrate. Many of these changes have been suggested to require a certain level of cellular plasticity.
In fact, cellular plasticity appears to be a process broadly used during regeneration. One cellular phenomenon involved in such cellular plasticity is transdifferentiation ( $\mathrm{Td})$. $\mathrm{Td}$ is a process by which a differentiated cell changes its cellular identity to stably adopt another specialised one (Eguchi and Kodama, 1993; Selman and Kafatos, 1974). Studying Td is of major interest for two reasons: 1) It occurs in a wide range of species and settings and addresses fundamental cellular properties - yet little is known about the mechanisms at play; and 2) Experimentally induced Td bears great promises as a method to produce replacement cells in damaged organs.

\section{Current picture and limitations to induced transdifferentia- tion in vertebrates}

In mammals, natural conversion of venous cells to coronary arteries has been observed (Red-Horse et al., 2010). Uesaka et al., (2016) also reviewed neurogenesis from Schwann cell precursors in the enteric nervous system. However, owing to the difficulty of studying such process in vivo, natural Td remains marginally described in mammals, and little is known about its implication in organ regeneration in human. More recently, a host of studies have explored how to obtain various cell types through in vitro induced transdifferentiation, following the TFs cocktail logic first used by Takahashi and Yamanaka for induced pluripotent reprogramming (Takahashi and Yamanaka, 2006), but this time using developmental cell fate determinants TFs involved in the differentiation of the target tissue (Takahashi and Yamanaka, 2006; Xu et al., 2015; Zhou et al., 2008). These studies have been useful to investigate the activities of the transcription factors used to reprogram cell identities, and have suggested that a combination of pioneer transcription factors and of repressor TFs that repress the initial identity expression programme, may be desirable. In addition, they have highlighted the importance of epigenetic factors (Becker and Jarriault, 2016; Mall and Wernig, 2017; Patel et al., 2012; Tursun et al., 2011). Besides a more in-depth understanding of the process, several milestones remain to be cleared for the study and potential therapeutic use of in vitro induced transdifferentiation in vertebrates: 1) On the technical side, and as emphasised earlier, a battery of cellular markers and reliable lineage-tracing methods are critically needed. Strategies to increase the transparency of poorly accessible organs will also help to follow induced transdifferentiation in vivo in vertebrates. 2) Determine which cells are best to use as starting cells. Answering this question requires understanding of whether the initial identity of the starting cells impacts on the final one, and whether and how it impacts on the efficiency of the transdifferentiation process. 3) Induce efficiently $\mathrm{Td}$, and safely. The current relatively poor efficiency of induced transdifferentiation begs the question of whether barriers to reprogramming exist. If so, understanding the nature of these barriers and whether their strength varies in different cell types will likely allow to design more efficient inducing protocols. In addition, the type of inducing cue and its mode of delivery (and removal) is paramount for potential future therapeutic applications. 4) Enable complete cell type conversion, at the genetic and epigenetic level. This will require sensitive techniques at the single cell level to ensure the selection of complete conversions. 5) Ensure stable cell type conversion over time, and in particular after the inducing reprogramming cue has been removed, a necessity for patients use. 6) Implement functional incorporation into existing tissue/ 
cellular network.

One way to improve the efficiency and completeness of the conversion and obtention of a stable functional final cell is to learn from the mechanisms that naturally ensure these important aspects in vivo, during natural Td events (Hajduskova et al., 2012; Zuryn et al., 2012). Natural Td is by essence efficient and robust, as demonstrated by the perfect regeneration of a lens in newts after 19 successive lensectomies (Sousounis et al., 2015). We will thus focus here on natural reprogramming events in $C$. elegans. For an overview of TF-induced reprogramming experiments in $C$. elegans, we refer the readers to recent reviews covering the topic (e.g. Spickard et al., 2018; Becker and Jarriault, 2016).

Natural transdifferentiation occurs during C. elegans development and is accessible at the much needed single-cell level

Owing to the description of the cellular lineage (Sulston and Horvitz, 1977), a putative Td event was postulated and confirmed during the normal development of $C$. elegans (Jarriault et al., 2008). Notably, a rectal epithelial cell called " $Y$ " transdifferentiates into a motoneuron called "PDA" (Fig. 3). We will also briefly review the conversion of differentiated glial cells (AMso) that give rise to male specific-interneurons through a cell division (Sammut et al., 2015), as it may represent another natural transdifferentiation event in the male. Below, we summarise the conceptual advances that the use of these models has brought.

\section{Y-to-PDA Td: a natural rectal-to-neuron transdifferentiation that involves discrete steps and dedifferentiation in the absence of cell division}

The $Y$ cell is born during embryogenesis at around 290 minutes of development after fertilisation (Sulston et al., 1983) (Fig. 3A). $Y$ is a rectal epithelial cell, expressing both epithelial and rectal markers (Jarriault et al., 2008). However, from the L2 to the L3 larval stages, $Y$ retracts from the rectum and migrates anteriorly and dorsally (Fig. 3 A-D and see the timeline in Fig. 3F) and transdifferentiates into a motoneuron with a precise subtype identity: PDA (Fig. 3E) (Jarriault et al., 2008; White et al., 1986). In a forerunner study, Y-to-PDA Td was shown to proceed through several steps even in absence of a cell division. This process first involves the erasure of the initial rectal identity, a sensu strictu dedifferentiation, before a step-wise redifferentiation that may mimic developmental differentiation (Richard et al., 2011). The first erasure of initial identity leads to a unipotent dedifferentiated intermediate (Y.0) rather than a multipotent one (Richard et al., 2011). No mixed identity stage is observed. These features (no mixed stage identity and sensu strictu dedifferentiation, uncoupled to increased cellular potential and reversion to stemness) appear to represent general principles, as preB-to-macrophage induced transdifferentiation proceeds similarly by first erasing the initial identity and expression programme before expressing the one of the final identity (Di Tullio et al., 2011). This occurs without retrodifferentiation, i.e no reversion to a previous and more potent precursor state (Di Tullio et al., 2011). In addition, lens regeneration in chicken and amphibians also involves transition through a dedifferentiated unipotent proliferative state (Dumont and Yamada, 1992; Sanchez Alvarado and Tsonis, 2006). In light of Td's therapeutic relevance, this is an exciting prospect as transition through unipotent cells might reduce the risk of tumorigenesis associated with loss of control of the cell's differentiation state.

\section{AMso to MCM Td: generation of new neurons in C. elegans males after one round of division of glial cells}

In males $C$. elegans a pair of glial cells (called the AMso cells for amphid socket cells) divide to give rise to two daughters with asymmetric fate: one is the adult amphid socket glial cell while the other adopts a neuronal identity (Sammut et al., 2015). These two new neurons made in males's head, called mystery cells of the male or MCM, express the neuropeptide pdf-1 and are involved in regulating sex-specific learning. MCM neurons are made in L4 at the time of sexual maturation. The use of a cell cycle marker together with ablation experiments conclusively showed that the AMso glial cells were the MCM progenitors. While further characterisation of the process will be required to fully characterise this event as Td as opposed to asymmetric cell division, it suggests that different transdifferentiation events, involving different initial identities, occur in the worm. Furthermore, it suggests that $\mathrm{Td}$ can proceed via a cell division or not in the same model organism. What does cell division add to the process? It is possible that DNA replication could facilitate $\mathrm{Td}$, for example through the erasure of certain epigenetic marks, or by forcing DNA-bound factors to be released. It can also provide a way to enable Td in only one of the daughter cells by asymmetrically segregating $\mathrm{Td}$ - or conversely cell identity maintenance - factors.

\section{The initiation of the process, materialised by a dedifferentia- tion, requires homologues of pluripotency factors that may define a conserved plasticity cassette}

Unbiased screening for mutants affected in Y-to-PDA Td identified four critical players in this process: SOX-2 the $C$. elegans HMG box containing SOX2 factor; the POU-containing CEH-6, the closest $C$. elegans POU factor to OCT4; EGL-27, the worm counterpart of MTA1; and SEM-4, a SALL4 orthologue (Kagias et al., 2012). Each of these factors is absolutely critical for the initiation of the $\mathrm{Td}$, corresponding to the dedifferentiation phase, to occur. Furthermore, EGL-27, SOX-2 and CEH-6 interact and conversely CEH-6/OCT interacts with SOX-2 and with the two isoforms of SEM-4/SALL suggesting that they could form a multiproteic complex (Kagias et al., 2012). Individually, the mammalian homologues of these factors are known for their key properties in inducing (for the OCT-4 and SOX-2 transcription factors), or maintaining (MTA1/2, a member of nuclear complexes with chromatin remodelling activities) pluripotency, or in enhancing the efficiency of pluripotent reprogramming (SALL4, a zinc finger transcription factor) (Chambers and Tomlinson, 2009; Liang et al., 2008; Wong et al., 2007). Furthermore, not only are these factors conserved but also the complex they form. In mammals, this complex, called NODE, is also found in Embryonic Stem (ES) cells where it is key to maintain their pluripotency (Liang et al., 2008). Altogether, these data suggest that these factors constitute a conserved plasticity cassette. It is possible that their primary or ancestral activity is to allow cells to reach a de-differentiated state, a property that is combined with endowing cells with pluripotency in mammals. Interestingly, several recent studies have used pulses of SOX2 and OCT4 in direct reprogramming processes and found that it increased the reprogramming efficiency (Efe et al., 2011; Han et al., 2015; Kim et al., 2008; Kurian et al., 2013; Li et al., 2014; Margariti et al., 2012; Thier et al., 2012; Zhu et al., 2014). In fact, of these factors, it is suspected that CEH-6/Oct4 and SOX-2 play an early pivotal role, and maybe successive roles, together with 
a Notch signal, to make the $Y$ cell competent to change its identity (Jarriault et al., 2008; and A. Ahier, T. Daniele, L.V. and S.J., personal communication). Thus, mimicking - at least in part - the mechanisms that exist naturally during transdifferentiation will likely improve our ability to induce it experimentally.

Epigenetic factors such as histone methylase SET-1 and demethylase JMJD.3.1 are required to ensure robustness of dedifferentiation and redifferentiation during transdifferentiation

Zuryn et al., 2014 identified mechanisms and factors involved in Td efficiency and robustness in vivo during $C$. elegans Y-to-PDA Td (Zuryn et al., 2014). Two complexes involved in histone methylation have been identified, that are not only important to ensure a perfect Td every time, but also to ensure its robustness against environmental variations: jmjd-3.1 which encodes an orthologue of the human di- and tri-demethylase (H3K27me3/me2 demethylase) Jmjd3; and the SET1A/SET1B orthologue, set-2. The SET2 protein is the catalytic subunit of SET-1 for H3K4 methylation. Timed rescue experiments showed that SET1 acts mediating both dedifferentiation and redifferentiation whereas JMJD-3.1 promotes only redifferentiation. Partitioning of these histone-modifying activities is achieved via timely degradation of nuclear JMJD-3.1 during dedifferentiation and interaction with step-specific transcription factors: the SET1 complex subunit WDR-5.1 interacts with factors of the NODE-like complex for dedifferentiation whereas a WDR5.1, JMJD-3.1 complex associates with UNC-3 for redifferentiation (Zuryn et al., 2014). Altogether, these results suggest that dynamic regulation of the $\mathrm{K} 27$ and $\mathrm{K} 4$ methylation state are critical to ensure perfect and robust Td. Again, these interactions and roles are likely to underlie conserved general principles of cellular plasticity. Previous studies in mice showed that Set1 potentiates Oct4 role during iPSCs reprogramming through interaction with Wdr5, while Jmjd3 inhibits the initial phases of pluripotent reprogramming, in line with its detrimental activity if it is not removed during the dedifferentiation phase in C. elegans (Ang et al., 2011; Mansour et al., 2012; Zhao et al., 2013).

\section{Conclusion}

In this review, we have focused on the advances in the understanding of wound healing and regeneration obtained in C. elegans. Interestingly, tissular and cellular repair might share some mechanistic similarities. For instances, common molecular players such as the kinases of the MAPK pathway, or signals such as calcium, seem to be important for both wound healing and axon regeneration in $C$. elegans. By contrast, Td activation during regeneration or normal development seems to be depending on other complex intrinsic or extrinsic mechanisms. How are these strategies encoded at the molecular level remains obscur. In mammals, few organs are able to regenerate large portions following acute injury, and wound healing is predominantly associated with the formation of scar tissue. The poor regenerative abilities of humans have led to therapeutic strategies such as the graft of tissues and organs to replace the damaged ones in patients. In parallel to grafts from donors, tissue engineering using embryonic stem cells (ESCs) or induced pluripotent stem cells (iPSCs) has recently been developed. Nevertheless, protocols to obtain mature cells and promote their functional integration to the endogenous tissue are still lacking. Furthermore, in addition to the potential persistence of pluripotent intermediates, safety issues are raised both for ESCs and iPSCs by possible chromosome abnormalities and by the use of viral vectors to induce reprogramming and directed differentiation, and ethical questions regarding the use of ESCs exist. Transdifferentiation offers another alternative to provide replacements cells, one that avoids the transition through a potentially dangerous pluripotent stage, and that can be carried on either by inducing endogenous cells close to the wound, or by grafting additional cells engineered at the bench. Model organisms have thus much to contribute to move us closer towards understanding the fundamental mechanisms naturally at play during tissue repair and regeneration. It is hoped that these studies will lead to the combined improvement of our abilities to stimulate the endogenous regenerative, limit scar formation and to provide replacement cells.

\section{Acknowledgements}

We are grateful to Nathalie Pujol and Jonathan Ewbank for insightful comments on the manuscript. SJ is a CNRS research director and research in the Jarriault lab is supported by an ERC CoG PlastiCell grant.

\section{References}

AHRINGER, J. (2006). Reverse genetics. In: WormBook: The Online Review of C. elegans Biology [Internet]. Pasadena (CA): WormBook; 2005-. Available from: https://www.ncbi.nlm.nih.gov/books/NBK19711/

ALAM, T., MARUYAMA, H., LI, C., PASTUHOV, S.I., NIX, P., BASTIANI, M., HISAMOTO, N. and MATSUMOTO, K. (2016). Axotomy-induced HIF-serotonin signalling axis promotes axon regeneration in C. elegans. Nat Commun 7: 10388.

ANG, Y.S., TSAI, S.Y., LEE, D.F., MONK, J., SU, J., RATNAKUMAR, K., DING, J., GE, Y., DARR, H., CHANG, B. et al., (2011). Wdr5 mediates self-renewal and reprogramming via the embryonic stem cell core transcriptional network. Cell 145: $183-197$

ATALA, A., IRVINE, D.J., MOSES, M. and SHAUNAK, S. (2010). Wound Healing Versus Regeneration: Role of the Tissue Environment in Regenerative Medicine. MRS Bull. 35.

BARKER, N. (2014). Adult intestinal stem cells: critical drivers of epithelial homeostasis and regeneration. Nat Rev Mol Cell Biol 15: 19-33.

BECKER, S.F. and JARRIAULT, S. (2016). Natural and induced direct reprogramming: mechanisms, concepts and general principles-from the worm to vertebrates. Curr Opin Genet Dev 40: 154-163.

BEGNAUD, S., CHEN, T., DELACOUR, D., MEGE, R.M. and LADOUX, B. (2016) Mechanics of epithelial tissues during gap closure. Curr Opin Cell Biol 42: 52-62.

BELY,A.E. and NYBERG, K.G. (2010). Evolution of animal regeneration: re-emergence of a field. Trends Ecol. Evol. 25(3): 161-170.

BRAFF, M.H., BARDAN, A., NIZET, V. and GALLO, R.L. (2005). Cutaneous defense mechanisms by antimicrobial peptides. J Invest Dermatol 125: 9-13.

BYRNE, A.B. and HAMMARLUND, M. (2017). Axon regeneration in C. elegans: Worming our way to mechanisms of axon regeneration. Exp Neurol 287: 300-309.

BYRNE, A.B., WALRADT, T., GARDNER, K.E., HUBBERT, A., REINKE, V. and HAMMARLUND, M. (2014). Insulin/IGF1 signaling inhibits age-dependent axon regeneration. Neuron 81: 561-573.

CHAMBERS, I. and TOMLINSON, S.R. (2009). The transcriptional foundation of pluripotency. Development 136: 2311-2322.

CHEN, Y., LIN, G. and SLACK, J.M. (2006). Control of muscle regeneration in the Xenopus tadpole tail by Pax7. Development 133: 2303-2313.

CHEN, Z.L., YU, W.M. and STRICKLAND, S. (2007). Peripheral regeneration. Annu Rev Neurosci 30: 209-233.

CHEN, L., WANG, Z., GHOSH-ROY, A., HUBERT, T., YAN, D., O'ROURKE, S. BOWERMAN, B., WU, Z., JIN, Y. and CHISHOLM, A.D. (2011). Axon regeneration pathways identified by systematic genetic screening in $C$. elegans. Neuron. 71(6):1043-1057.

CHEN, L., CHUANG, M., KOORMAN, T., BOXEM, M., JIN, Y. and CHISHOLM, A.D. (2015). Axon injury triggers EFA-6 mediated destabilization of axonal microtubules 
via TACC and doublecortin like kinase. eLife 4:e08695.

CHERA, S., BARONNIER, D., GHILA, L., CIGLIOLA, V., JENSEN, J.N., GU, G., FURUYAMA, K., THOREL, F., GRIBBLE, F.-M., REIMANN, F. et al., (2014). Diabetes recovery by age-dependent conversion of pancreatic delta-cells into insulin producers. Nature 514: 503-507.

CHISHOLM, A.D. and XU, S. (2012). The Caenorhabditis elegans epidermis as a model skin. II: differentiation and physiological roles. Wiley Interdiscip Rev Dev Biol. 1(6):879-902.

CHISHOLM, A.D. (2013). Cytoskeletal dynamics in Caenorhabditis elegans axon regeneration. Annu Rev Cell Dev Biol 29: 271-297.

CHISHOLM, A.D., HUTTER, H., JIN, Y. and WADSWORTH, W.G. (2016). The Genetics of Axon Guidance and Axon Regeneration in Caenorhabditis elegans. Genetics 204: 849-882.

CHOU, Y.H., PAN, S.Y., YANG, C.H. and LIN, S.L. (2014). Stem cells and kidney regeneration. J Formos Med Assoc 113: 201-209.

CHUANG, M., GONCHAROV, A., WANG, S., OEGEMA, K., JIN, Y. and CHISHOLM, A.D. (2014). The microtubule minus-end-binding protein patronin/PTRN-1 is required for axon regeneration in C. elegans. Cell Rep 9: 874-883.

CHUANG, M., HSIAO I, T., TONG, A., XU, S. and CHISHOLM, A.D. (2016). DAPK interacts with Patronin and the microtubule cytoskeleton in epidermal development and wound repair. eLife 5: 23.

CHUNG, S.H., AWAL, M.R., SHAY, J., MCLOED, M.M., MAZUR, E. and GABEL, C.V. (2016). Novel DLK-independent neuronal regeneration in Caenorhabditis elegans shares links with activity-dependent ectopic outgrowth. Proc. Natl. Acad. Sci. USA 13: E2852-2860.

CLARK, A.G., MILLER, A.L., VAUGHAN, E., YU, H.Y., PENKERT, R. and BEMENT, W.M. (2009). Integration of single and multicellular wound responses. Curr Biol 19: 1389-1395.

CORR, D.T., GALLANT-BEHM, C.L., SHRIVE, N.G. and HART, D.A. (2009). Biomechanical behavior of scar tissue and uninjured skin in a porcine model. Wound Repair Regen 17: 250-259.

CORSI, A.K., WIGHTMAN, B. and CHALFIE, M. (2015). A Transparent window into biology: A primer on Caenorhabditis elegans. Genetics 200: 1-31.

COUILLAULT, C., PUJOL, N., REBOUL, J., SABATIER, L., GUICHOU, J.F., KOHARA, Y. and EWBANK, J.J. (2004). TLR-independent control of innate immunity in Caenorhabditis elegans by the TIR domain adaptor protein TIR-1, an ortholog of human SARM. Nat Immunol 5: 488-494.

DITULLIO, A., VU MANHA, T.P., SCHUBERTA, A., CASTELLANOB, G., MÅNSSONC, R. and GRAFA, T. (2011). CCAAT/enhancer binding protein $\alpha$ (C/EBP $\alpha$-induced transdifferentiation of pre-B cells into macrophages involves no overt retrodifferentiation. Proc. Natl. Acad. Sci. USA 108: 17016-17021.

DICKINSON, D.J. and GOLDSTEIN, B. (2016). CRISPR-Based Methods for Caenorhabditis elegans Genome Engineering. Genetics 202: 885-901.

DIERKING, K., POLANOWSKA, J., OMI, S., ENGELMANN, I., GUT, M., LEMBO, F., EWBANK, J.J. and PUJOL, N. (2011). Unusual regulation of a STAT protein by an SLC6 family transporter in C. elegans epidermal innate immunity. Cell Host Microbe 9: 425-435.

DODD, W., TANG, L., LONE, J.C., WIMBERLY, K., WU, C.W., CONSALVO, C., WRIGHT, J.E., PUJOL, N., CHOE, K.P. (2018). A Damage Sensor Associated with the Cuticle Coordinates Three Core Environmental Stress Responses in Caenorhabditis elegans. Genetics 208: 1467-1482.

DUMONT, J.N. and YAMADA, T. (1992). Dedifferentiation of Iris Epithelial Cells Dev. Biol. 29: 385-401.

DUNNILL, C., PATTON, T., BRENNAN, J., BARRETT, J., DRYDEN, M., COOKE, J., LEAPER, D. and GEORGOPOULOS, N.T. (2017). Reactive oxygen species (ROS) and wound healing: the functional role of ROS and emerging ROS-modulating technologies for augmentation of the healing process. Int Wound J 14: 89-96.

EFE, J.A., HILCOVE, S., KIM, J., ZHOU, H., OUYANG, K., WANG, G., CHEN, J. and DING, S. (2011). Conversion of mouse fibroblasts into cardiomyocytes using a direct reprogramming strategy. Nat Cell Biol 13: 215-222.

EGUCHI, G. and KODAMA, R. (1993). Transdifferentiation Curr. Opin. Cell Biol. 5: 1023-1028.

EL BEJJANI, R. and HAMMARLUND, M. (2012). Notch signaling inhibits axon regeneration. Neuron 73: 268-278.

EMING, S.A., MARTIN, P. and TOMIC-CANIC, M. (2014). Wound repair and regenera- tion: mechanisms, signaling, and translation. Sci Transl Med 6: 1-35.

ENES, J., LANGWIESER, N., RUSCHEL, J., CARBALLOSA-GONZALEZ, M.M., KLUG, A., TRAUT, M.H., YLERA, B., TAHIROVIC, S., HOFMANN, F., STEIN, V. et al., (2010). Electrical activity suppresses axon growth through $\mathrm{Ca}(\mathrm{v}) 1.2$ channels in adult primary sensory neurons. Curr Biol 20: 1154-1164.

ENGELMANN, I. and PUJOL, N. (2010). Innate immunity in C. elegans. Adv Exp Med Biol 708: 105-121.

ENYEDI, B. and NIETHAMMER, P. (2015). Mechanisms of epithelial wound detection Trends Cell Biol 25: 398-407.

FAY, D.S. (2013). Classical genetic methods. WormBook: 1-58

FAY, D.S. and GEROW, K. (2013). A biologist's guide to statistical thinking and analysis. WormBook: 1-54.

FERGUSON, M.W. and O'KANE, S. (2004). Scar-free healing: from embryonic mechanisms to adult therapeutic intervention. Philos Trans $R$ Soc Lond B Bio Sci 359: 839-850.

FREUND, P., SCHMIDLIN, E., WANNIER, T., BLOCH, J., MIR, A., SCHWAB, M.E. and ROUILLER, E.M. (2006). Nogo-A-specific antibody treatment enhances sprouting and functional recovery after cervical lesion in adult primates. NatMed 12: 790-792.

GABEL, C.V., ANTOINE, F., CHUANG, C.F., SAMUEL, A.D. and CHANG, C. (2008). Distinct cellular and molecular mechanisms mediate initial axon development and adult-stage axon regeneration in C. elegans. Development 135: 1129-1136.

GARGETT, C.E., NGUYEN, H.P. and YE, L. (2012). Endometrial regeneration and endometrial stem/progenitor cells. Rev Endocr Metab Disord 13: 235-251.

GHOSH-ROY, A., GONCHAROV, A., JIN, Y. and CHISHOLM, A.D. (2012). Kinesin-13 and tubulin posttranslational modifications regulate microtubule growth in axon regeneration. Dev Cell 23: 716-728.

GHOSH-ROY, A., WU, Z., GONCHAROV, A., JIN, Y. and CHISHOLM, A.D. (2010). Calcium and Cyclic AMP Promote Axonal Regeneration in Caenorhabditis elegans and Require DLK-1 Kinase. J Neurosci. 30: 3175-3183.

HAJDUSKOVA, M., AHIER, A., DANIELE, T. and JARRIAULT, S. (2012). Cell plasticity in Caenorhabditis elegans: from induced to natural cell reprogramming. Genesis 50: 1-17.

HAMMARLUND, M., JORGENSEN, E.M. and BASTIANI, M.J. (2007). Axons break in animals lacking beta-spectrin. $J$ Cell Biol 176: 269-275.

HAMMARLUND, M., NIX, P., HAUTH, L., JORGENSEN, E.M. and BASTIANI, M. (2009). Axon regeneration requires a conserved MAP kinase pathway. Science 323: 802-806.

HAN, F., LI, X., SONG, D., JIANG, S., XU, Q. and ZHANG, Y. (2015). SCNT versus iPSCs: proteins and small molecules in reprogramming. Int J Dev Bio/59: 179-186.

HAO, J.C., YU, T.W., FUJISAWA, K., CULOTTI, J.G., GENGYO-ANDO, K., MITANI, S., MOULDER, G., BARSTEAD, R., TESSIER-LAVIGNE M. and BARGMANN, C.I. (2001). C. elegans slit acts in midline, dorsal-ventral, and anterior-posterior guidance via the SAX-3/Robo receptor. Neuron 32(1): 25-38.

HENSON, J.H., NAZARIAN, R., SCHULBERG, K.L., TRABOSH, V.A., KOLNIK, S.E., BURNS, A.R. and MCPARTLAND, K.J. (2002). Wound closure in the lamellipodia of single cells: mediation by actin polymerization in the absence of an actomyosin purse string. Mol Biol Cell 13: 1001-1014.

HISAMOTO, N. and MATSUMOTO, K. (2017). Signal transduction cascades in axon regeneration: insights from C. elegans. Curr Opin Genet Dev 44: 54-60.

HOBERT, O. (2013). The neuronal genome of Caenorhabditis elegans. WormBook 1-106.

HORN, A., VAN DER MEULEN, J.H., DEFOUR, A., HOGARTH, M., SREETAMA S.C., REED, A., SCHEFFER, L., CHANDEL, N.S. and JAISWAL, J.K. (2017) Mitochondrial redox signaling enables repair of injured skeletal muscle cells. Sci Signal 10: eaaj1978

HUANG, L.S. and STERNBERG, P.W. (2006). Genetic dissection of developmental pathways. WormBook: 1-19.

HUNT, P.R. (2017). The C. elegans model in toxicity testing. J App/ Toxicol37: 50-59.

ITOH, A., HORIUCHI, M., BANNERMAN, P., PLEASURE, D. and ITOH, T. (2009). Impaired regenerative response of primary sensory neurons in ZPK/DLK genetrap mice. Biochem Biophys Res Commun 383: 258-262.

JACYNIAK, K., MCDONALD, R.P. and VICKARYOUS, M.K. (2017). Tail regeneration and other phenomena of wound healing and tissue restoration in lizards. $J$ Exp Biol 220: 2858-2869. 
JARRIAULT, S., SCHWAB, Y. and GREENWALD, I. (2008). A C. elegans model for epithelial-neuronal transdifferentiation. Proc. Natl. Acad. Sci. USA 105:3790-3795

JOPLING, C., BOUE, S. and IZPISUA BELMONTE, J.C. (2011). Dedifferentiation, transdifferentiation and reprogramming: three routes to regeneration. Nat Rev Mol Cell Biol 12: 79-89.

KAGIAS, K., AHIER, A., FISCHER, N. and JARRIAULT, S. (2012). Members of the NODE (Nanog and Oct4-associated deacetylase) complex and SOX-2 promote the initiation of a natural cellular reprogramming event in vivo. Proc. Natl. Acad. Sci. USA 109 6596-6601.

KERR, R.A. (2006). Imaging the activity of neurons and muscles. WormBook: 1-13.

KIM, J., EFEA, J.A., ZHUA, S., TALANTOVAC, M., YUANA, X., SHUFEN, W., LIPTON, S.A., ZHANGD, K. and DINGA, S. (2008). Direct reprogramming of mouse fibroblasts to neural progenitors. Proc. Natl. Acad. Sci. USA 108: 7838-7843.

KNOWLTON, W.M., HUBERT, T., WU, Z., CHISHOLM, A.D. and JIN, Y. (2017). A Select Subset of Electron Transport Chain Genes Associated with Optic Atrophy Link Mitochondria to Axon Regeneration in Caenorhabditis elegans. Front Neurosci 11: 263

KOTTON, D.N. and MORRISEY, E.E. (2014). Lung regeneration: mechanisms, applications and emerging stem cell populations. Nat Med 20: 822-832.

KRAGL, M., KNAPP, D., NACU, E., KHATTAK, S., MADEN, M., EPPERLEIN, H.H. and TANAKA, E.M. (2009). Cells keep a memory of their tissue origin during axolotl limb regeneration. Nature 460: 60-65.

KURIAN, L., AGUIRRE, A., SANCHO-MARTINEZ, I., BENNER, C., HISHIDA, T., NGUYEN, T.B., REDDY, P., NIVET, E., et al., (2013). Conversion of human fibroblasts to angioblast-like progenitor cells. Nat. Methods 10: 77-83.

LAI, M.Z. and CHEN, R.H. (2014). Regulation of inflammation by DAPK. Apoptosis 19: 357-363.

LI, C., HISAMOTO, N., NIX, P., KANAO, S., MIZUNO, T., BASTIANI, M., MATSUMOTO, K. (2012). The growth factor $S V H-1$ regulates axon regeneration in C. elegans via the JNK MAPK cascade. Nat Neurosci. 15(4): 551-557.

LI, K., ZHU, S., RUSS, H.A., XU, S., XU, T., ZHANG, Y., MA, T., HEBROK, M. and DING, S. (2014). Small molecules facilitate the reprogramming of mouse fibroblasts into pancreatic lineages. Cell Stem Cell 14: 228-236.

LIANG, J., WAN, M., ZHANG, Y., GU, P., XIN, H., JUNG, S.Y., QIN, J., WONG, J., COONEY, A.-J., LIU, D. et al., (2008). Nanog and Oct4 associate with unique transcriptional repression complexes in embryonic stem cells. Nat Cell Biol 10: 731-739.

LIU, K., LU, Y., LEE, J.K., SAMARA, R., WILLENBERG, R., SEARS-KRAXBERGER, I., TEDESCHI, A., PARK, K.K., JIN, D., CAI, B. et al., (2010). PTEN deletion enhances the regenerative ability of adult corticospinal neurons. Nat Neurosci 13: $1075-1081$.

MALL, M. and WERNIG, M. (2017). The novel tool of cell reprogramming for applications in molecular medicine. J Mol Med (Berl) 95: 695-703.

MANGONI, M.L., MCDERMOTT, A.M. and ZASLOFF, M. (2016). Antimicrobial peptides and wound healing: biological and therapeutic considerations. Exp Dermatol 25: 167-173.

MANN, C.J., PERDIGUERO, E., KHARRAZ, Y., AGUILAR, S., PESSINA, P., SERRANO, A.L. and MUNOZ-CANOVES, P. (2011). Aberrant repair and fibrosis development in skeletal muscle. Skelet Muscle 1: 1-21.

MANSOUR, A.A., GAFNI, O., WEINBERGER, L., ZVIRAN, A., AYYASH, M., RAIS, Y., KRUPALNIK, V., ZERBIB, M., AMANN-ZALCENSTEIN, D., MAZA, I. et al., (2012). The H3K27 demethylase Utx regulates somatic and germ cell epigenetic reprogramming. Nature 488: 409-413.

MARGARITI, A., WINKLER, B., KARAMARITI, E., ZAMPETAKI, A., TSAI, T.N., BABAN, D., RAGOUSSIS, J., HUANG, Y., HAN, J.D., ZENG, L. et al., (2012). Direct reprogramming of fibroblasts into endothelial cells capable of angiogenesis and reendothelialization in tissue-engineered vessels. Proc. Natl. Acad. Sci. USA 109: 13793-13798.

MARTIN, P. (1997). Wound healing--aiming for perfect skin regeneration. Science 276: 75-81.

MASCRE, G., DEKONINCK, S., DROGAT, B., YOUSSEF, K.K., BROHEE, S., SOTIROPOULOU, P.A., SIMONS, B.D. and BLANPAIN, C. (2012). Distinct contribution of stem and progenitor cells to epidermal maintenance. Nature 489: 257-262.

MATEJUK, A. (2017). Skin Immunity. Arch Immunol Ther Exp (Warsz). 66(1): 45-54. MICHALOPOULOS, G.K. (2007). Liver regeneration. J Cell Physiol 213: 286-300.
MIDWOOD, K.S., WILLIAMS, L.V. and SCHWARZBAUER, J.E. (2004). Tissue repair and the dynamics of the extracellular matrix. Int JBiochem Cell Bio/36: 1031-1037.

MORRISON, J.I., BORG, P. and SIMON, A. (2010). Plasticity and recovery of skeletal muscle satellite cells during limb regeneration. FASEB J 24: 750-756.

NEUMANN, S., BRADKE, F., TESSIER-LAVIGNE, M. and BASBAUM, A.I. (2002). Regeneration of Sensory Axons within the Injured Spinal Cord Induced by Intraganglionic cAMP Elevation. Neuron 34: 885-893.

NEUMANN, B., COAKLEY, S., GIORDANO-SANTINI, R., LINTON, C., LEE, E.S., NAKAGAWA, A., XUE, D. and HILLIARD, M.A. (2015). EFF-1-mediated regenerative axonal fusion requires components of the apoptotic pathway. Nature 517:219-222.

NIX, P., HISAMOTO, N., MATSUMOTO, K. and BASTIANI, M. (2011). Axon regeneration requires coordinate activation of p38 and JNK MAPK pathways. Proc. Natl. Acad. Sci. USA 108: 10738-10743.

NIX, P., HAMMARLUND, M., HAUTH, L., LACHNIT, M., JORGENSEN, E.M. and BASTIANI, M. (2014). Axon regeneration genes identified by RNAi screening in C. elegans. J Neurosci 34: 629-645.

O'REILLY, L.P., LUKE, C.J., PERLMUTTER, D.H., SILVERMAN, G.A. and PAK, S.C. (2014). C. elegans in high-throughput drug discovery. Adv Drug Deliv Rev 69-70: 247-253

OIKONOMOU, G. and SHAHAM, S. (2011). The glia of Caenorhabditis elegans. Glia 59: 1253-1263.

OREN-SUISSA, M., GATTEGNO, T., KRAVTSOV, V. and PODBILEWICZ, B. (2017). Extrinsic Repair of Injured Dendrites as a Paradigm for Regeneration by Fusion in Caenorhabditis elegans. Genetics 206: 215-230.

PARK, K., LUO, J.M., HISHEH, S., HARVEY, A.R. and CUI, Q. (2004). Cellular mechanisms associated with spontaneous and ciliary neurotrophic factor-cAMPinduced survival and axonal regeneration of adult retinal ganglion cells. $J$ Neurosci 24: 10806-10815.

PARK, K.K., LIU, K., HU, Y., SMITH, P.D., WANG, C., CAI, B., XU, B., CONNOLLY, L., KRAMVIS, I., SAHIN, M. et al., (2008). Promoting Axon Regeneration in the Adult CNS by Modulation of the PTEN/mTOR Pathway. Science 322: 963-966.

PATEL, T., TURSUN, B., RAHE, D.P. and HOBERT, O. (2012). Removal of Polycomb repressive complex 2 makes $C$. elegans germ cells susceptible to direct conversion into specific somatic cell types. Cell Rep 2: 1178-86.

PINAN-LUCARRE, B., GABEL, C.V., REINA, C.P., HULME, S.E., SHEVKOPLYAS, S.S., SLONE, R.D., XUE, J., QIAO, Y., WEISBERG, S., ROODHOUSE, K. et al., (2012). The core apoptotic executioner proteins CED-3 and CED-4 promote initiation of neuronal regeneration in Caenorhabditis elegans. PLOS Biol 10: 3-13.

PLIKUS, M.V., GUERRERO-JUAREZ, C.F., ITO, M., LI, Y.R., DEDHIA, P.H., ZHENG, Y., SHAO, M., GAY, D.L., RAMOS, R., HSI, T.C. et al., (2017). Regeneration of fat cells from myofibroblasts during wound healing. Science 355: 748-752.

PUJOL, N., CYPOWYJ, S., ZIEGLER, K., MILLET, A., ASTRAIN, A., GONCHAROV, A., JIN, Y., CHISHOLM, A.D. and EWBANK, J.J. (2008a). Distinct innate immune responses to infection and wounding in the C. elegans epidermis. Curr Biol 18 : 481-489.

PUJOL, N., ZUGASTI, O., WONG, D., COUILLAULT, C., KURZ, C.L., SCHULENBURG, H. and EWBANK, J.J. (2008b). Anti-fungal innate immunity in C. elegans is enhanced by evolutionary diversification of antimicrobial peptides. PLoS Pathog 4: e1000105.

PUJOL, N., DAVIS, P.A., EWBANK, J.J. (2012). The Origin and Function of Anti-Funga Peptides in C. elegans: Open Questions. Front Immunol. 3: 237.

RED-HORSE, K., UENO, H., WEISSMAN, I.L. and KRASNOW, M.A. (2010). Coronary arteries form by developmental reprogramming of venous cells. Nature 464 549-553.

RICHARD, J.P., ZURYN, S., FISCHER, N., PAVET, V., VAUCAMPS, N. and JARRIAULT, S. (2011). Direct in vivo cellular reprogramming involves transition through discrete, non-pluripotent steps. Development 138: 1483-1492.

RICHARDSON, R., METZGER, M., KNYPHAUSEN, P., RAMEZANI, T., SLANCHEV, K., KRAUS, C., SCHMELZER, E. and HAMMERSCHMIDT, M. (2016). Reepithelialization of cutaneous wounds in adult zebrafish combines mechanisms of wound closure in embryonic and adult mammals. Development 143: 2077-2088.

SADRI, A.R., JESCHKE, M.G. and AMINI-NIK, S. (2016). Advances in Liver Regeneration: Revisiting Hepatic Stem/Progenitor Cells and Their Origin. Stem Cells Int 2016: 1-9.

SAKAGAMI, H., SUZUKI, H., KAMATA, A., OWADA, Y., FUKUNAGA, K., MAYANAGI, 
H. and KONDO, H. (2006). Distinct spatiotemporal expression of EFA6D, a guanine nucleotide exchange factor for ARF6, among the EFA6 family in mouse brain. Brain Res 1093: 1-11

SAMMUT, M., COOK, S.J., NGUYEN, K.C.Q., FELTON, T., HALL, D.H., EMMONS, S.W., POOLE, R.J. and BARRIOS, A. (2015). Glia-derived neurons are required for sex-specific learning in C. elegans. Nature 526: 385-390.

SANCHEZ ALVARADO, A. and TSONIS, P.A. (2006). Bridging the regeneration gap: genetic insights from diverse animal models. Nat Rev Genet 7: 873-884.

SANDOVAL-GUZMAN, T., WANG, H., KHATTAK, S., SCHUEZ, M., ROENSCH, K., NACU, E., TAZAKI, A., JOVEN, A., TANAKA, E.M. and SIMON, A. (2014). Fundamental differences in dedifferentiation and stem cell recruitment during skeletal muscle regeneration in two salamander species. Cell Stem Cell 14: 174-187.

SASAKI, M., ABE, R., FUJITA, Y., ANDO, S., INOKUMA, D. and SHIMIZU, H. (2008). Mesenchymal stem cells are recruited into wounded skin and contribute to wound repair by transdifferentiation into multiple skin cell type. J Immunol180:2581-2587.

SELMAN, K. and KAFATOS, F.-C. (1974). Transdifferentiation in the labial gland of silk moths: is DNA required for cellular metamorphosis? Cell Differ. 3: 81-94.

SHAYE, D.D. and GREENWALD, I. (2011). OrthoList: A Compendium of C. elegans Genes with Human Orthologs. PLoS One 6: 1-12.

SHIEH, S.J. and CHENG, T.C. (2015). Regeneration and repair of human digits and limbs: fact and fiction. Regeneration (Oxf) 2: 149-168.

SHIN, J.E., CHO, Y., BEIROWSKI, B., MILBRANDT, J., CAVALLI, V. and DIANTONIO, A. (2012). Dual leucine zipper kinase is required for retrograde injury signaling and axonal regeneration. Neuron 74: 1015-1022.

SIMON, A. and TANAKA, E.M. (2013). Limb regeneration. Wiley Interdiscip Rev Dev Biol. 2(2): 291-300.

SJOBERG, J. and KANJE, M. (1989). Insulin-like growth factor (IGF-1) as a stimulator of regeneration in the freeze-injured rat sciatic nerve. Brain Res. 485: 102-108.

SNIDER, W.D., FENG-QUAN, Z., ZHONG, J. and MARKUS, A. (2002). Signaling the Pathway to Regeneration. Neuron 35: 13.

SORENSEN, O.E., THAPA, D.R., ROUPE, K.M., VALORE, E.V., SJOBRING, U., ROBERTS, A.A., SCHMIDTCHEN, A. and GANZ, T. (2006). Injury-induced innate immune response in human skin mediated by transactivation of the epidermal growth factor receptor. J Clin Invest 116: 1878-1885.

SOUSOUNIS, K., FENG, Q., MANISHA C, Y., JOSE LUIS, M., FUBITO, T., CHIKAFUMI, C., YUKIKO, E., GORO, E. and PANAGIOTIS A, T. (2015). A robust transcriptional program in newts undergoing multiple events of lens regeneration throughout their lifespan. eLife 4: 1-17.

SPENCER, T. and FILBIN, M.T. (2004). A role for CAMP in regeneration of the adult mammalian CNS. J. Anat 204: 49-55.

SPICKARD, E.A., JOSHI, P.M., ROTHMAN, J.H. (2018). The multipotency-to-commitment transition in Caenorhabditis elegans - implications for reprogramming from cells to organs. FEBS Lett. 592: 838-851.

STIERNAGLE, T. (2006). Maintenance of C. elegans. WormBook: 1-11.

SULSTON, J.E., HORVITZ H.R. (1977). Post-embryonic cell lineages of the nematode, Caenorhabditis elegans. Dev Biol. 56(1): 110-156.

SULSTON, J.E., SCHIERENBERG, E., WHITE, J.G., THOMSON, J.N. (1983). The embryonic cell lineage of the nematode Caenorhabditis elegans. Dev Biol. 100(1): 64-119.

TAFFONI, C. and PUJOL, N. (2105). Mechanisms of innate immunity in C. elegans epidermis. Tissue Barriers 5;3(4): e1078432.

TAKAHASHI, K. and YAMANAKA, S. (2006). Induction of pluripotent stem cells from mouse embryonic and adult fibroblast cultures by defined factors. Cell 126: 663-676.

TAKEUCHI, O. and AKIRA, S. (2010). Pattern recognition receptors and inflammation. Cell 140: 805-820

TANAKA, E.M. and REDDIEN, P.W. (2011). The cellular basis for animal regeneration. Dev Cell 21: 172-185.

TANG, N.H. and CHISHOLM, A.D. (2016). Regulation of Microtubule Dynamics in Axon Regeneration: Insights from C. elegans. F1000 Res. 5: 1-10.

THIER, M., WORSDORFER, P., LAKES, Y.B., GORRIS, R., HERMS, S., OPITZ, T., SEIFERLING, D., QUANDEL, T., HOFFMANN, P., NOTHEN, M.M. et al., (2012). Direct conversion of fibroblasts into stably expandable neural stem cells. Cell Stem Cell 10: 473-479.
THOREL, F., NEPOTE, V., AVRIL, I., KOHNO, K., DESGRAZ, R., CHERA, S. and HERRERA, P.L. (2010). Conversion of adult pancreatic alpha-cells to beta-cells after extreme beta-cell loss. Nature 464: 1149-1154.

TONG, A., LYNN, G., NGO, V., WONG, D., MOSELEY, S.L., EWBANK, J.J., GONCHAROV, A., WU, Y.C., PUJOL, N. and CHISHOLM, A.D. (2009). Negative regulation of Caenorhabditis elegans epidermal damage responses by death-associated protein kinase. Proc. Natl. Acad. Sci. USA 106: 1457-1461.

TORPE, N., NORGAARD, S., HOYE, A.M. and POCOCK, R. (2017). Developmental Wiring of Specific Neurons Is Regulated by RET-1/Nogo-A in Caenorhabditis elegans. Genetics 205: 295-302.

TURSUN, B., PATEL, T., KRATSIOS, P. and HOBERT, O. (2011). Direct conversion of $C$. elegans germ cells into specific neuron types. Science 331: 304-308.

UESAKA, T., YOUNG, H.M., PACHNIS, V. and ENOMOTO, H. (2016). Development of the intrinsic and extrinsic innervation of the gut. Dev Biol 417: 158-167.

VERDFI, E., BUTL, M. and NAVARRO, X. (1995). The effect of aging on efferent nerve fibers regeneration in mice. Brain Res. 3: 76-82.

WHITE, J., SOUTHGATE, E., THOMSON, J. and BRENNER, S. (1986). The structure of the nervous system of the nematode Caenorhabditis elegans. Philos Trans $A$ Soc Lond B Biol Sci. 314: 1-340.

WONG, C.C., GASPAR-MAIA, A., RAMALHO-SANTOS, M. and REIJO-PERA, R.A. (2007). High-Efficiency Stem Cell Fusion-Mediated Assay Reveals Sall4 as an Enhancer of Reprogramming. PLOS ONE 3(4): e1955.

WU, P., ALIBARDI, L. and CHUONG, C.M. (2014). Regeneration of reptilian scales after wounding: neogenesis, regional difference, and molecular modules. Regeneration 1: 15-26.

WU, Z., GHOSH-ROY, A., YANIK, M.F., ZHANG, J.Z., JIN, Y. and CHISHOLM, A.D. (2007). Caenorhabditis elegans neuronal regeneration is influenced by life stage, ephrin signaling, and synaptic branching. Proc. Natl. Acad. Sci. USA 104: 15132-15137.

XIAOWEI, H., NINGHUI, Z., WEI, X., YIPING, T. and LINFENG, X. (2006). The experimental study of hypoxia-inducible factor-1alpha and its target genes in spinal cord injury. Spinal Cord 44: 35-43.

XU, S. and CHISHOLM, A.D. (2011). A Galphaq-Ca(2)(+) signaling pathway promotes actin-mediated epidermal wound closure in C. elegans. Curr Biol21: 1960-1967.

XU, S., HSIAO, T.I. and CHISHOLM, A.D. (2012). The wounded worm: Using C. elegans to understand the molecular basis of skin wound healing. Worm 1(2):134-138.

$\mathrm{XU}$, S. and CHISHOLM, A.D. (2014a). C. elegans epidermal wounding induces a mitochondrial ROS burst that promotes wound repair. Dev Cell 31: 48-60.

$\mathrm{XU}, \mathrm{S}$. and CHISHOLM, A.D. (2014b). Methods for skin wounding and assays for wound responses in C. elegans. J Vis Exp 94.

$\mathrm{XU}, \mathrm{J}$., DU, Y. and DENG, H. (2015). Direct lineage reprogramming: strategies, mechanisms, and applications. Cell Stem Cell 16: 119-134.

YAN, D., WU, Z., CHISHOLM, A.D. and JIN, Y. (2009). The DLK-1 kinase promotes mRNA stability and local translation in C. elegans synapses and axon regeneration. Cell 138: 1005-1018

YANGER, K., ZONG, Y., MAGGS, L.R., SHAPIRA, S.N., MADDIPATI, R., AIELLO N.M., THUNG, S.N., WELLS, R.G., GREENBAUM, L.E. and STANGER, B.Z. (2013). Robust cellular reprogramming occurs spontaneously during liver regeneration. Genes Dev 27: 719-724.

YANIK, M.-F., HULUSI, C., CINAR, H., CINAR, H.N., CHISHOLM, A.D., JIN, Y. and BEN YAKAR, A. (2004). Functional regeneration after laser axotomy. Nature 432: 822.

YAU, K.W., VAN BEUNINGEN, S.F., CUNHA-FERREIRA, I., CLOIN, B.M., VAN BATTUM, E.Y., WILL, L., SCHATZLE, P., TAS, R.P., VAN KRUGTEN, J., KATRUKHA, E.A. et al., (2014). Microtubule minus-end binding protein CAMSAP2 controls axon specification and dendrite development. Neuron 82: 1058-1073.

YOCHEM, J. (2006). Nomarski images for learning the anatomy, with tips for mosaic analysis. Wormbook: 1-47.

ZHAO, W., LI, Q., AYERS, S., GU, Y., SHI, Z., ZHU, Q., CHEN, Y., WANG, H.Y. and WANG, R.F. (2013). Jmjd3 inhibits reprogramming by upregulating expression of INK4a/Arf and targeting PHF20 for ubiquitination. Cell 152: 1037-1050.

ZHOU, Q., BROWN, J., KANAREK, A., RAJAGOPAL, J., MELTON, D.A. (2008). In vivo reprogramming of adult pancreatic exocrine cells to beta-cells. Nature 455(7213): 627-632.

ZHU, S., REZVANI, M., HARBELL, J., MATTIS, A.N., WOLFE, A.R., BENET, L.Z., WILLENBRING, H. and DING, S. (2014). Mouse liver repopulation with hepato- 
cytes generated from human fibroblasts. Nature 508: 93-97.

ZIEGLER, K., KURZ, C.L., CYPOWYJ, S., COUILLAULT, C., POPHILLAT, M., PUJOL, N. and EWBANK, J.J. (2009). Antifungal innate immunity in C. elegans: PKCdelta links G protein signaling and a conserved p38 MAPK cascade. Cell Host Microbe 5: 341-352.

ZOU, C.G., TU, Q., NIU, J., JI, X.L. and ZHANG, K.Q. (2013a). The DAF-16/FOXO transcription factor functions as a regulator of epidermal innate immunity. PLoS Pathog. 9: e1003660.

ZOU, Y., CHIU, H., ZINOVYEVA, A., AMBROS, V., CHUANG, C.F. and CHANG, C. (2013b). Developmental decline in neuronal regeneration by the progressive change of two intrinsic timers. Science 340: 372-376.

ZUGASTI, O. and EWBANK, J.J. (2009). Neuroimmune regulation of antimicrobial peptide expression by a noncanonical TGF-beta signaling pathway in Caenorhabditis elegans epidermis. Nat Immunol 10: 249-256.

ZUGASTI, O., BOSE, N., SQUIBAN, B., BELOUGNE, J., KURZ, C.L., SCHROEDER, F.C., PUJOL, N. and EWBANK, J.J. (2014). Activation of a G protein-coupled receptor by its endogenous ligand triggers the innate immune response of Caenorhabditis elegans. Nat. Immunol. 15: 833-838.

ZURYN, S., DANIELE, T. and JARRIAULT, S. (2012). Direct cellular reprogramming in Caenorhabditis elegans: facts, models, and promises for regenerative medicine. Wiley Interdiscip Rev Dev Biol 1: 138-152.

ZURYN, S., AHIER, A., PORTOSO, M., REDHOUSE WHITE, E., MORIN, M., MARGUERON, R. and JARRIAULT, S. (2014). Sequential histone modifying activities determine the robustness of transdifferentiation. Science 345: 826-829. 


\section{Further Related Reading, published previously in the Int. J. Dev. Biol.}

Single cell analysis of the inner ear sensory organs

Ofer Yizhar-Barnea and Karen B. Avraham

Int. J. Dev. Biol. (2017) 61: 205-213

Reprogramming cell fate: a scientific journey from viral enhancers to the master gene regulator Oct4 - an interview with Hans R. Schöler

Michele Boiani

Int. J. Dev. Biol. (2010) 54: 1685-1695

Regeneration and pattern formation - an interview with Susan Bryant

Michael K. Richardson and Cheng Ming Chuong

Int. J. Dev. Biol. (2009) 53: 827-833

Formation of retinal pigment epithelium in vitro by transdifferentiation of neural retina cells.

M Opas, J R Davies, Y Zhou and E Dziak

Int. J. Dev. Biol. (2001) 45: 633-642

Notch-related genes in animal development.

M Lardelli, R Williams and U Lendahl

Int. J. Dev. Biol. (1995) 39: 769-780

Basic fibroblast growth factor as one of the essential factors regulating lens transdifferentiation of pigmented epithelial cells.

M Hyuga, R Kodama and G Eguchi

Int. J. Dev. Biol. (1993) 37: 319-326

The ability of the epithelium of diencephalic origin to differentiate into cells of the ocular lens.

G Juric-Lekic, F Bulic-Jakus, B Kablar and A Svajger

Int. J. Dev. Biol. (1991) 35: 231-237

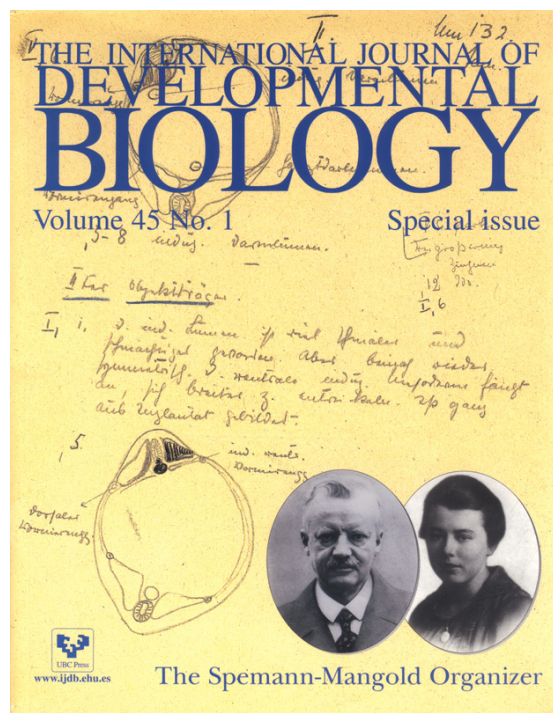

5 yr ISI Impact Factor $(2016)=2.421$

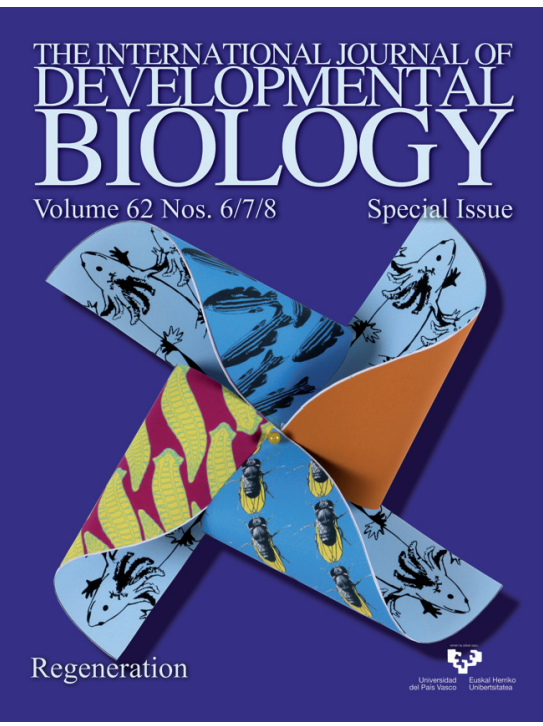

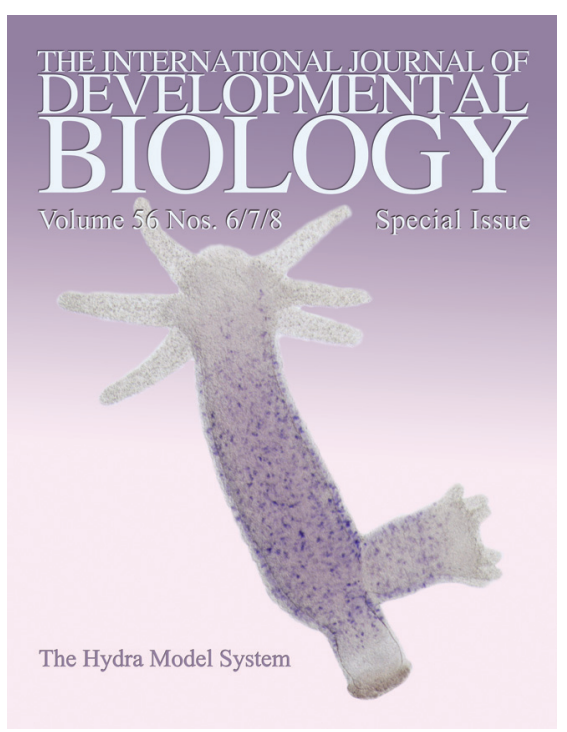

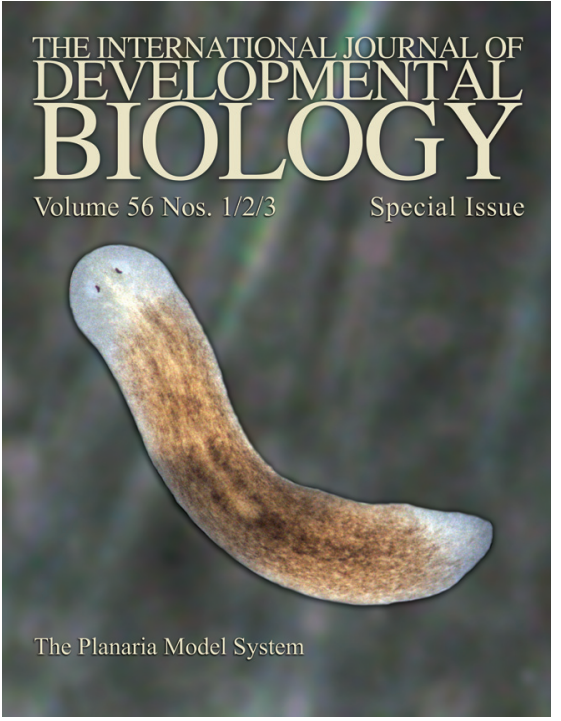

